\title{
An Adaptogen: Withaferin A Ameliorates in Vitro and in Vivo Pulmonary Fibrosis by Modulating the Interplay of Fibrotic, Matricelluar Proteins, and Cytokines
}

\author{
Swarna Bale, Pooladanda Venkatesh, Manoj Sunkoju and Chandraiah Godugu* \\ Department of Regulatory Toxicology, National Institute of Pharmaceutical Education and Research, Hyderabad, India
}

Pulmonary fibrosis (PF) is chronic lung disease with only two FDA approved clinically available drugs, with limited safety profile. Inadequate therapy motivated us to explore the effect of vimentin inhibitor Withaferin $A$, as an anti-fibrotic agent against TGF- $\beta 1$-induced in vitro fibrotic events and Bleomycin induced in vivo fibrosis with an emphasis on epithelial to mesenchymal transition (EMT), extracellular matrix deposition (ECM), inflammation, and angiogenesis. In vitro EMT and fibrotic events were induced by TGF- $\beta 1$ in alveolar epithelial cells and human fetal lung fibroblasts followed by treatment

OPEN ACCESS

Edited by:

Narasaiah Kolliputi, University of South Florida,

United States

Reviewed by:

Rajasekaran Subbiah,

Anna University, India

Vaidehi Jatin Thanawala,

Vapogenix, Inc., United States

*Correspondence:

Chandraiah Godugu chandragodugu@gmail.com

Specialty section: This article was submitted to Respiratory Pharmacology, a section of the journal

Frontiers in Pharmacology

Received: 11 October 2017 Accepted: 06 March 2018

Published: 22 March 2018

Citation:

Bale S, Venkatesh P, Sunkoju M and Godugu C (2018) An Adaptogen: Withaferin A Ameliorates in Vitro and in Vivo Pulmonary Fibrosis by Modulating the Interplay of Fibrotic, Matricelluar Proteins, and Cytokines.

Front. Pharmacol. 9:248.

doi: 10.3389/fphar.2018.00248 with Withaferin $\mathrm{A}(0.25,0.5$, and $1 \mu \mathrm{M}$ concentrations) to explore its anti-fibrotic effects. In vivo potential of Withaferin A (2 and $4 \mathrm{mg} / \mathrm{kg}$ ) was assessed in murine model of Bleomycin induced PF. All the parameters and molecular studies related to PF were performed at the end of treatment period. Withaferin A treatment reduced the progression of PF by modulating the EMT related cell markers both in vivo and in vitro. Withaferin $A$ ameliorated the expression of inflammatory cytokines including $\mathrm{NF}-\mathrm{\kappa B}$ p65, IL-1 $\beta$ and TNF- $\alpha$, as well as attenuated the expression of pro-fibrotic proteins including CTGF, collagen 1A2, collagen $3 \mathrm{~A} 1$, and fibronectin. Expression of angiogenic factors like VEGF, FAK, p38 MAPK, and PLC- $\gamma 1$ were also inhibited by Withaferin A. Phosphorylation of Smad 2/3 induced by TGF- $\beta 1$ and Bleomycin were significantly inhibited. Withaferin A suppressed expression of pro-inflammatory, pro-fibrotic, and pro-angiogenic mediators and also reduced the ECM deposition. In a nutshell, Withaferin A could probably prove as an efficient and potential therapeutic against PF.

Keywords: Withaferin A, pulmonary fibrosis, epithelial to mesenchymal transition, extracellular matrix, inflammation, angiogenesis

\section{INTRODUCTION}

Pulmonary fibrosis (PF) is a chronic, progressive and irreversible lethal medical problem hallmarked by alveolar disruption, excess scarring and edema of lungs that may significantly contribute to critical respiratory failure (American Thoracic Society and European Respiratory Society, 2002; King et al., 2011). PF is common amongst various interstitial lung diseases with

Abbreviations: BLM, Bleomycin; ECM, extracellular matrix; EMT, epithelial to mesenchymal transition; PF, pulmonary fibrosis; TGF- $\beta$, transforming growth factor- $\beta$; WFA, Withaferin A. 
poor average reported survival rate of 2-3 years (Ley et al., 2011). Etiological factors of PF are not well-established and some of the reported findings promoting PF include exposure to chemotherapeutics and other xenobiotics such as silica, asbestos, and paraquat (Wilson and Wynn, 2009). Persisting respiratory disorders like asthma, chronic obstructive pulmonary disease, severe lung injury, environmental factors, and uncontrolled wound healing also culminate in the progression of PF (Chilosi et al., 2012). Though noticeable efforts have been consistently made to develop novel therapeutic strategies for treatment of PF including steroids and immunosuppressant agents, they could not sufficiently intervene the fibrotic progression and thus are considered only as supportive therapies. Esbriet (Perfenidone), a potential TGF- $\beta$ inhibitor and Ofev (Nintedanib), a tyrosine kinase inhibitor are the only two USFDA approved drugs available to treat PF till date (Ley et al., 2011). Unfortunately, these drugs could not satisfactorily overcome the progression of disease and moreover they exhibit gastrointestinal, skin, and liver-related adverse effects (Jiang et al., 2012; Richeldi et al., 2015). Despite the advances in the arena of PF, the urge to develop efficient therapeutics prevails.

Withaferin $\mathrm{A}$ is a natural steroidal lactone, rejuvenating tonifier, immunomodulator and a pre-dominant bioactive constituent obtained from Withania somnifera (Ashwagandha) which exhibits an array of potential biological activities including anti-inflammatory, anti-invasive, pro-apoptotic, and anti-fibrotic effects and is remarkably safe (Vanden Berghe et al., 2012; Hahm et al., 2014; Madhusudan et al., 2016; Kim et al., 2017). WFA exhibits potent anti-inflammatory effect by downregulating central inflammatory mediator, nuclear factor kappa light chain enhancer of activated B cells $(\mathrm{NF}-\kappa \mathrm{B})$ and other cytokines which has been well-elucidated in vitro and in vivo studies (Heyninck et al., 2014). Above all, WFA is a pre-clinically proven vimentin and TGF- $\beta$ inhibitor but its role in PF is not yet explored (Challa et al., 2012). Thus, the present study is aimed at demonstrating the role of WFA in mitigating PF.

Epithelial to mesenchymal transition and extracellular matrix (ECM) are considered as crucial developmental milestones in PF wherein, a pivotal fibrogenic cytokine TGF- $\beta$ is aberrantly expressed, which in turn triggers EMT process thereby enhancing ECM deposition mediated by both Smad dependent and independent pathways (Verrecchia and Mauviel, 2002; Kasai et al., 2005; Kolosova et al., 2011; Todd et al., 2012; Zhang, 2017). Though decisive factors of PF are questionable, some of the mechanisms that have been found to be imperative in disease progression include inflammation, oxidative stress, deregulated ECM and EMT signaling. Therefore, targeting these pathways may lead to discovery of potent novel compounds with anti-fibrotic activity, thus diminishing the existing void in treatment of PF. In light of key evidences of WFA as a vimentin, TGF- $\beta$ and NF- $\kappa \mathrm{B}$ modulator, the present study investigates the potential of WFA in ameliorating PF with an emphasis on matricellular and fibrotic proteins. Mechanisms of pharmacological intervention by WFA were evaluated through molecular techniques like immunohistochemistry, immunocytochemistry, ELISA, and western blotting.

\section{MATERIALS AND METHODS}

\section{Reagents and Antibodies}

Withaferin A was procured from Aptus laboratories (Hyderabad, India) and TGF- $\beta 1$ was obtained from Bio-legend (United States); Bleomycin sulfate was procured from Cipla labs (India); Masson's trichrome staining kit, Sirius red, Chloramine-T, Hydroxyproline, and Ehrlich reagent were procured from Sigma-Aldrich, Anti-ZO-1, anti-E-cadherin, anti-Smad 2/3, anti-p Smad 2/3, anti-vimentin, anti-NF-кB p65, anti-p VEGF, anti-p p38 MAPK, anti-p FAK, and anti-p PLC $\gamma 1$ were procured from Cell Signaling Technology, while anti-Col 1A2, anti-Col 3A1, anti-smooth muscle actin, anti-CTGF, anti-fibronectin, and anti-TGF- $\beta 1$ were obtained from Santa Cruz Biotechnology (United States). ELISA kits were purchased from eBioscience, United States. TGF- $\beta$ bioplex kit was procured from Merck-Millipore. Rest of the chemicals and reagents were of analytical grade and obtained from commercially available sources.

\section{Cell Culture}

HFL1 cells were procured from ATCC (ATCC ${ }^{\circledR}$ CCL153 $^{\text {TM }}$ ) and A549 cells were purchased from National Centre for Cell Science (NCCS, Pune, India). HFL1 and A549 cells were cultured in F-12K medium (ATCC) and RPMI medium (Sigma-Aldrich, United States) respectively; supplemented with $10 \%$ fetal bovine serum and $1 \%$ anti-biotic solution (Invitrogen, United States). TGF- $\beta 1$ was selected to induce fibrotic events at a concentration of $10 \mathrm{ng} / \mathrm{mL}$ in both HFL1 and A549 cell lines. WFA was dissolved in DMSO and a stock concentration of $10 \mathrm{mM}$ was prepared, stored at $-20^{\circ} \mathrm{C}$ and diluted with respective media at required concentrations before use. Cells were cultured and treated with WFA at various concentrations $(0.25,0.5$, and $1 \mu \mathrm{M}) 2 \mathrm{~h}$ prior to induction of TGF- $\beta 1$ and incubated for $24 \mathrm{~h}$ at $37^{\circ} \mathrm{C}$ maintained in $5 \% \mathrm{CO}_{2}$ incubator. All the experiments were performed in three internal replicates.

\section{Cell Viability Assay}

The effect of WFA on viability of HFL1 and A549 cells was evaluated using MTT assay (Maurya et al., 2011). Briefly, 10,000 cells per well of HFL1 and A549 were seeded in 96-well plates and after $24 \mathrm{~h}$ of incubation, WFA was treated at concentrations in serial dilution from 0.78 to $50 \mu \mathrm{M}$ ( 7 serial dilutions). Post $24 \mathrm{~h}$ of incubation, MTT solution was added at a final concentration of $0.5 \mathrm{mg} / \mathrm{mL}$, incubated for $4 \mathrm{~h}$ followed by addition of DMSO to dissolve the formazan crystals then incubated for $30 \mathrm{~min}$ and absorbance was measured at $570 \mathrm{~nm}$ with a multi-mode spectrophotometer. Experiments were performed thrice in triplicates and data was expressed as percentage cell viability versus concentration of the compound by taking control cells as $100 \%$ viable cells.

\section{Cell Migration Assay}

The ability of the cells to migrate was assessed using cell migration assay. Briefly, HFL1 cells were plated at a density of 
$1 \times 10^{5}$ cells in 12 well culture plates and allowed to grow till $70-80 \%$ confluence was attained. The monolayer of the cells was disrupted to create a gap in a straight line using a sterile $200 \mu \mathrm{L}$ micropipette tip, and the wells were washed with PBS to remove the detached cells (Choi and Kim, 2015). Cells were treated with TGF- $\beta 1$ and WFA for $24 \mathrm{~h}$. Images of the gap between cells were captured at time points of 0 and $24 \mathrm{~h}$, the width of the gap was measured in all groups using microscopic scaling and quantified using image J software.

\section{Immunocytochemistry}

Cells were cultured on cover slips and after $24 \mathrm{~h}$ of plating, cells underwent starvation (media with no serum) for $6 \mathrm{~h}$, followed by WFA treatment $2 \mathrm{~h}$ before TGF- $\beta$ induction. After $24 \mathrm{~h}$ of incubation, cells were fixed with $4 \%$ paraformaldehyde for 15 min, washed with PBS and permeabilized with $0.1 \%$ Triton $\mathrm{X}-100$ in PBS for about $30 \mathrm{~min}$. Cells were washed twice with PBS and incubated for $1 \mathrm{~h}$ with blocking solution (3\% BSA in PBS). The blocked cells were incubated with primary antibodies anti-vimentin and anti- $\alpha$ SMA at 1:100 dilutions in 3\% BSA overnight at $4^{\circ} \mathrm{C}$. On the following day, cells were washed thrice with PBS, incubated with secondary Fluorescein isothiocyanate (FITC) anti-rabbit and rhodamine anti-mouse antibodies for $2 \mathrm{~h}$ at room temperature. Cells were washed thrice in PBS (5 min per wash) and then cover slips were mounted with vectashield hardset antifade mounting medium ${ }^{\circledR}$ with DAPI (Vector Labs, Burlingame, CA, United States) on a glass slide. Slides were visualized using a confocal microscope (Leica TCS SP8 Laser Scanning Spectral Confocal).

\section{TGF- $\beta$ Signaling 6-Plex Magnetic Bead Assay}

Stimulated and unstimulated cell tissue lysate were used to detect changes in phosphorylated Smad2 (Ser465/Ser467) and Smad3 (Ser423/Ser425) using the Luminex system. This assay was performed with customized highly sensitive MILLIPLEXMAP signaling 6-plex magnetic bead human TGF- $\beta$ kit (Cat \# 48-614MAG Millipore) based on protocol provided by manufacturer.

\section{Animals and Treatment}

Animal studies were carried out in male Swiss albino mice, 8 weeks old, purchased from Teena labs (Hyderabad, India) and acclimatized for a week before study initiation. Animals were allowed free access to food and water ad libitium and maintained with 12/12 h light and dark cycle. All the animal experiments were approved by institutional animal ethics committee (IAEC) of NIPER-Hyderabad, in accordance with approved protocol. Animals were randomly divided into five groups $(n=12)$ : (1) Control group, (2) BLM alone group $(1 \mathrm{U} / \mathrm{kg} /$ day $\times 2)$, (3) BLM+WFA (2 mg/kg), (4) BLM+WFA (4 mg/kg), and (5) WFA alone $(4 \mathrm{mg} / \mathrm{kg})$. Mice were administered with $1 \mathrm{U} / \mathrm{kg} /$ day $\times 2$ of BLM via oropharyngeal route while WFA was administered once daily from day 1 for 28 days by intraperitoneal (i.p.) route. To avoid pulmonary hemorrhage due to $\mathrm{CO}_{2}$ method of euthanasia, animals were euthanized using 5\% Isoflurane
(SurgiVet isoflurane vaporizer-4215061) before bronchoalveolar lavage (BAL) fluid collection. Lungs were harvested after euthanizing animals with $\mathrm{CO}_{2}$ asphyxiation on the day of termination for the pathological and molecular studies.

\section{Bronchoalveolar Lavage Fluid Parameters}

Bronchoalveolar lavage fluid was collected thrice from each animal by passing $1 \mathrm{~mL}$ of ice-cold PBS into the trachea, followed by gentle aspiration of the fluid by inserting a catheter in the trachea (Bale et al., 2016). The percentage recovery of lavage fluid was approximately $85 \%$ and did not differ among the animal groups significantly. BAL fluid collected from each animal was pooled and subjected to total and differential cell count using automatic hematology Advia 2120i system (Siemens). Subsequently, BAL fluid was centrifuged at $300 \mathrm{~g}$, for $10 \mathrm{~min}$ at $4^{\circ} \mathrm{C}$, and the supernatant was stored at $-80^{\circ} \mathrm{C}$ or used immediately to perform total protein content of BAL using Bradford assay and lactate dehydrogenase (LDH) levels were estimated using commercially available kit (Accurex, India).

\section{Lung to Body Weight Index}

Animal body weights were recorded at the termination of the study. Lungs were collected after necropsy; cleaned and weighed. Lung weight index was calculated as ratio of lung weight to body weight.

\section{Lung Biochemical Assays}

\section{Estimation of Glutathione (GSH) Content}

Ellman's method was used to measure glutathione content in lung tissue supernatants (Moron et al., 1979). Lung tissues were homogenized using TRIS buffer and Ellman's reagent [5, 5' -dithiobis-2-nitro benzoic acid (DTNB) solution] was added to the supernatants containing GSH buffer $(125 \mathrm{mM}$ potassium phosphate of $\mathrm{pH} 8.4$ ), incubated for $5 \mathrm{~min}$ in dark and absorbance was measured at $412 \mathrm{~nm}$ using spectrophotometer (Spectramax M4, Molecular Devices, United States). Values obtained were compared with series of reduced glutathione standards (concentration range: 500 to $7.8 \mu \mathrm{M}$ ). Results were expressed as $\mu \mathrm{M} / \mathrm{mg}$ of lung protein.

\section{Estimation of Nitric Oxide Levels}

Nitric oxide levels were estimated using Griess reagent (Guevara et al., 1998). Lung tissues were homogenized using TRIS buffer, supernatants were collected and mixed with equal proportions of Griess reagent, incubated in dark for $10 \mathrm{~min}$ and absorbance was measured at $548 \mathrm{~nm}$ without any delay. NO levels were expressed as $\mu \mathrm{M} / \mathrm{mg}$ of lung protein with sodium nitrite taken as standard (concentration range: 100 to $1.5 \mu \mathrm{M}$ ).

\section{Collagen Determination Using Hydroxyproline Assay}

Assay for estimating hydroxyproline levels was performed to detect collagen levels as discussed (Limjunyawong et al., 2014) with slight modifications. Lung tissues were weighed, homogenized and subjected to acid hydrolysis. Oxidation of the tissues was done using Chloramine- $T$ for $15 \mathrm{~min}$ followed by Ehrlich reagent addition. Samples were incubated 
at $60^{\circ} \mathrm{C}$ for $20 \mathrm{~min}$, cooled and absorbance was read at $550 \mathrm{~nm}$. Concentrations of samples were calculated using concentration-absorbance curve of hydroxyproline standards (concentration range: 125 to $3.9 \mu \mathrm{g} / \mathrm{mL}$ ).

\section{Sircol Assay for Collagen Estimation}

Lung tissues were homogenized and supernatant was collected to which collagen binding dye was added and incubated for $1 \mathrm{~h}$ at $37^{\circ} \mathrm{C}$, followed by centrifugation. Obtained visible red pellet was dissolved in $100 \%$ ethanol to remove excess dye and was again subjected to centrifugation. Subsequently, the pellet was dissolved in $0.5 \mathrm{M}$ sodium chloride solution, incubated for $30 \mathrm{~min}$ at $37^{\circ} \mathrm{C}$ and absorbance was measured at $540 \mathrm{~nm}$ using spectrophotometer. Values were expressed as $\mu \mathrm{M} / \mathrm{mg}$ normalized with lung protein content performed using Bradford assay.

\section{Pathological Investigations}

Left lung tissues collected on the day of sacrifice were fixed in $10 \%$ non-buffered formalin solution and embedded in paraffin. Sections of $5 \mu \mathrm{m}$ thickness were cut using microtome and subjected to H\&E staining to observe pathologic morphological changes in the tissue. Further, to estimate the collagen deposition in the lung tissues, sections were stained with Masson's trichrome and picrosirius red while the mast cell accumulation in lungs was estimated by toluidine blue staining as per the standard protocols (Veerappan et al., 2012; Godugu et al., 2013; Vogel et al., 2015).

\section{Quantification of TNF- $\alpha$ and IL-1 $\beta$ by ELISA}

Lung tissues were weighed, homogenized, and subjected to centrifugation maintaining at $4^{\circ} \mathrm{C}$. Tissue supernatants were stored at $-80^{\circ} \mathrm{C}$ in aliquots or used immediately to estimate cytokine expression. Pro-inflammatory cytokines including TNF- $\alpha$ and IL- $1 \beta$ were evaluated for their expression in lung tissues using commercially available ELISA kits (eBioscience, TNF- $\alpha$ Catalogue No-50-173-67; IL-1 $\beta$ Catalogue No-50-1128807).

\section{Immunohistochemistry}

Lung tissue slides were deparaffinised in xylene and rehydrated in series of gradient alcohol. Antigen retrieval was performed by heating sections for $10 \mathrm{~min}$ in citrate buffer followed by eliminating endogenous peroxidase using $3 \% \mathrm{H}_{2} \mathrm{O}_{2}$. The sections were incubated with 3\% BSA to avoid non-specific background prior to incubation with primary antibodies including mouse anti- $\alpha$-SMA antibody $(1: 100)$, rabbit anti-vimentin antibody (1:100), and rabbit anti-NF-кB p65 for $30 \mathrm{~min}$ at room temperature. HRP-linked polymer detection system was used to develop color reaction, sections were then counterstained with hematoxylin, mounted with resinous mounting solution and visualized for immunoreactivity and percentage of positive cells were calculated (Godugu et al., 2017).

\section{Western Blot Analysis}

Procedure for western blot analysis was adopted from (Patel et al., 2015) with slight modifications. Briefly, cells were lysed using radio immunoprecipitation assay lysis buffer (RIPA) (SigmaAldrich) and lung tissues were homogenized using tissue protein extraction reagent (TEPER) lysis buffer, mixed with protease and phosphatase inhibitors (Sigma-Aldrich) maintained at $4^{\circ} \mathrm{C}$, to obtain supernatants. Protein concentration was determined using Bicinchonic acid commercial assay kit (Sigma-Aldrich). Equal amounts of proteins were separated on SDS polyacrylamide gels and transferred onto polyvinyldifluoride (PVDF) membrane (Bio-Rad). After transfer, protein of interest was blocked for non-specific binding (3\% BSA) and incubated with primary antibody overnight. Blots were washed thrice with TBST, each time for $10 \mathrm{~min}$ and incubated with HRP-conjugated secondary antibody for $1 \mathrm{~h}$ at room temperature. Membranes were visualized using enhanced chemiluminescence reagents by chemdoc (Vilber fusion $\mathrm{Fx}$ ) and the protein bands were subjected to densitometry analysis using Image J software. The membranes were probed with $\beta$-actin antibody as an internal control. Each blot shown represents at least three independent experiments.

\section{Statistical Analysis}

All results (in vitro and in vivo) were expressed as mean \pm SEM of three independent experiments. Statistical analysis was performed by ANOVA followed by Tukey's post hoc test. All statistical analyses were performed using GraphPad Prism ${ }^{\circledR}$ Version 5 software. Probability values less than 0.05 levels were considered as statistically significant.

\section{RESULTS}

\section{Effect of WFA on Cell Viability and TGF- $\beta 1$ Induced Cell Migration}

In vitro effects of WFA on cell viability were tested on A549 (human alveolar adenocarcinomic basal epithelial cells) and HFL1 (human fetal lung fibroblasts) cells; $\mathrm{IC}_{50}$ values were found to be $3.46 \pm 0.2$ and $4.45 \pm 0.12 \mu \mathrm{M}$ respectively at $24 \mathrm{~h}$ studied using MTT [3-(4, 5-dimethylythiazol-2-yl)-2, 5-diphenyl tetrazolium bromide] assay (Figure 1A). Based on the results of cell viability assay performed at various concentrations, maximum safe concentrations $(<1 \mu \mathrm{M})$ were selected so that viability of the cells was not affected upon WFA treatment and concentration dependent studies were performed with WFA at $0.25,0.5$, and $1 \mu \mathrm{M}$ in cultured cells. TGF- $\beta 1$ stimulation promotes the rate of cellular migration (Barrett et al., 2017). Therefore, to delineate the effect of WFA on cell migration, wound scratch assay was performed with WFA at concentrations of $0.25,0.5$, and $1 \mu \mathrm{M}$ on TGF- $\beta 1(10 \mathrm{ng} / \mathrm{mL})$ treatment for $24 \mathrm{~h}$ in HFL1 cells. WFA ameliorated TGF- $\beta 1$ induced rate of cell migration (Figures $\mathbf{1 B}, \mathbf{C}$ ) in a concentration dependent manner demonstrating the decrease in the inducible cell proliferation rate by WFA. It was also evident that there was a significant decrease in migration rate of HFL1 cells by WFA at 0.5 and $1 \mu \mathrm{M}$, compared to control fibroblast cells suggesting the inhibitory effect of WFA on constitutive cell proliferation where in WFA attenuated the basal cell migration rate of fibroblasts. 

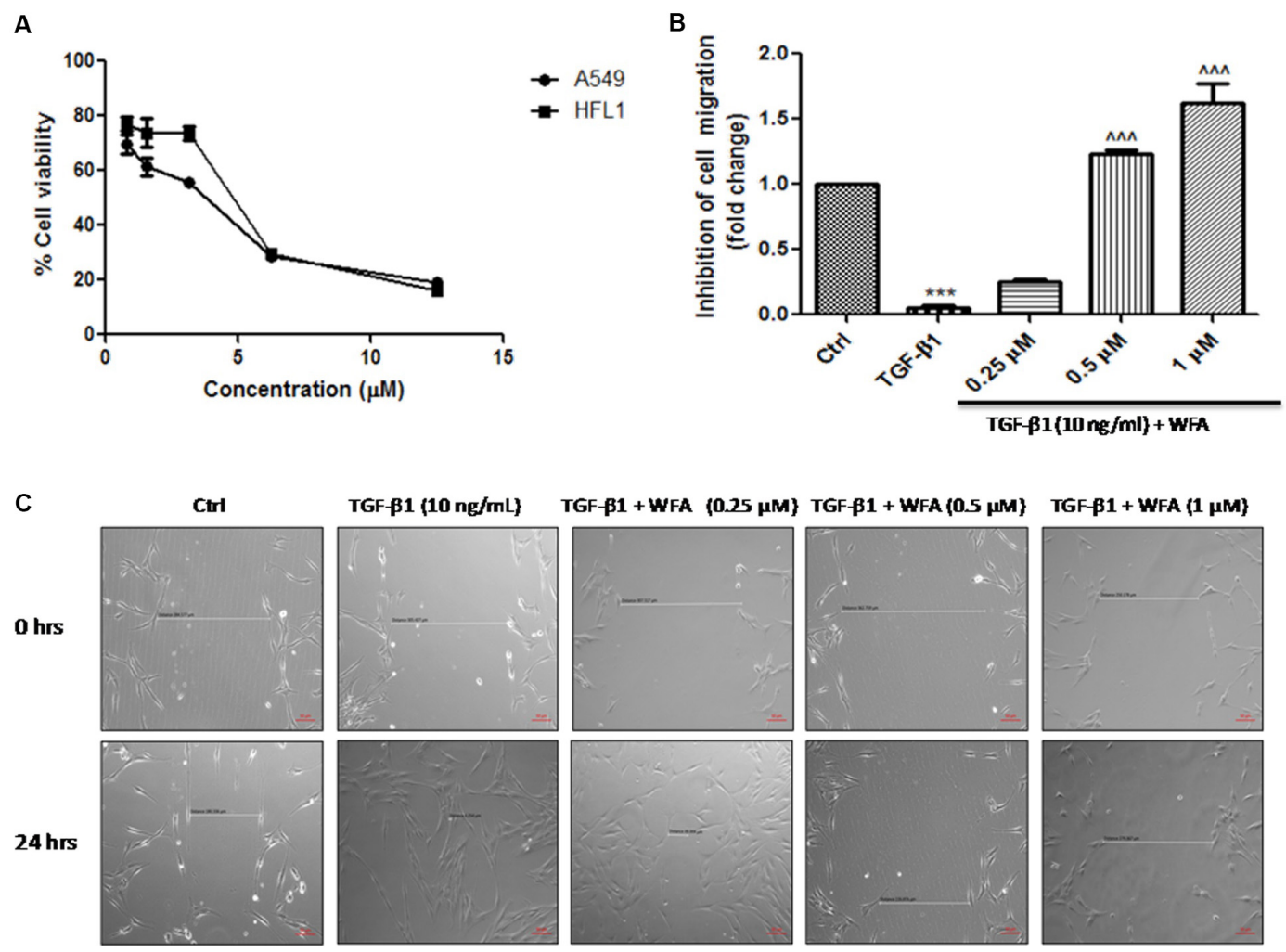

FIGURE 1 | Effect of WFA on cell viability and migration after $24 \mathrm{~h}$ of TGF- $\beta 1$ stimulation. (A) Effect of WFA on cell viability of A549 and HFL1 cell lines, (B) graphical representation denoting the effect of WFA on inhibition of cell migration of HFL1 cells analyzed using Image $\mathrm{J}$ software, and (C) representation of phase contrast images of cells depicting the role of WFA in inhibiting TGF- $\beta 1$ induced cell migration. Statistical significance was tested using one way ANOVA, *** $p<0.001$ of TGF- $\beta 1$ versus control; ${ }^{\wedge} \uparrow p<0.001$ of WFA with TGF- $\beta 1$ versus TGF- $\beta 1$ alone.

\section{WFA Ameliorated the EMT Related Proteins on TGF- $\beta 1$ Induction in Vitro}

EMT, the transformation of fibroblasts to myofibroblasts is crucial in pathogenesis of fibrotic disorders of different organs (Li et al., 2016). In in vitro studies, TGF- $\beta 1$ is a key cytokine used to induce EMT events in various fibroblasts, specifically in A549 cells where EMT plays a prominent role. Therefore expression of some of the EMT related proteins were investigated upon WFA treatment on both A549 and HFL1 cell lines (Figure 2). TGF- $\beta 1$ stimulated cells resulted in significant damping of both epithelial markers E-cadherin, Zonula occludens (ZO-1) and enhanced expression of vimentin. WFA treatment increased the expression of E-cadherin as well as $\mathrm{ZO}-1$ and decreased the expression of mesenchymal vimentin in A549 cells concentration dependently.

Consistent with the effect of EMT inhibition of WFA on A549 cells, WFA also decreased the expression of key mesenchymal markers including $\alpha$-smooth muscle actin ( $\alpha$-SMA) and fibronectin in TGF- $\beta 1$ induced fibroblast cells in concentration dependent manner. To further confirm the effects of WFA on EMT markers, immunofluoresence assay was carried out on fibroblast cells (Figure 3). Results of immunocytochemistry assay clearly revealed the enhanced expression of mesenchymal markers $\alpha$-SMA and vimentin in TGF- $\beta 1$ treated cells compared to control cells. The distribution and expression of both $\alpha$-SMA and vimentin were decreased upon WFA treatment (Figure 3) which was in consistency with the key findings of EMT events obtained by western blot.

\section{WFA Attenuated the Expression of Pro-fibrotic Proteins on TGF- $\beta 1$ Induction in Lung Fibroblasts via Smad Signaling Cascade}

As WFA ameliorated EMT in vitro (A549 and HFL1), we further examined the molecular mechanism through which WFA suppresses TGF- $\beta 1$ induced EMT. TGF- $\beta 1$ is a key fibrotic cytokine that drives EMT by excess ECM synthesis (Moustakas and Heldin, 2016). TGF- $\beta 1$ stimulation phosphorylates Smad $2 / 3$ and forms heterocomplex with Smad 4 which modulates the target gene expression (Nakao et al., 1997). We assessed the effects of WFA on TGF- $\beta 1 /$ Smad signaling pathway and as expected, there was a marked increase of $\mathrm{p}$-Smad $2 / 3$ protein expression in TGF- $\beta 1$ treated cells compared to control cells and WFA significantly attenuated the phosphorylation of Smad 2/3 (Figures 4A,I).

Connective tissue growth factor (CTGF) is recognized as a major matricellular protein induced by TGF $\beta 1$, functions 


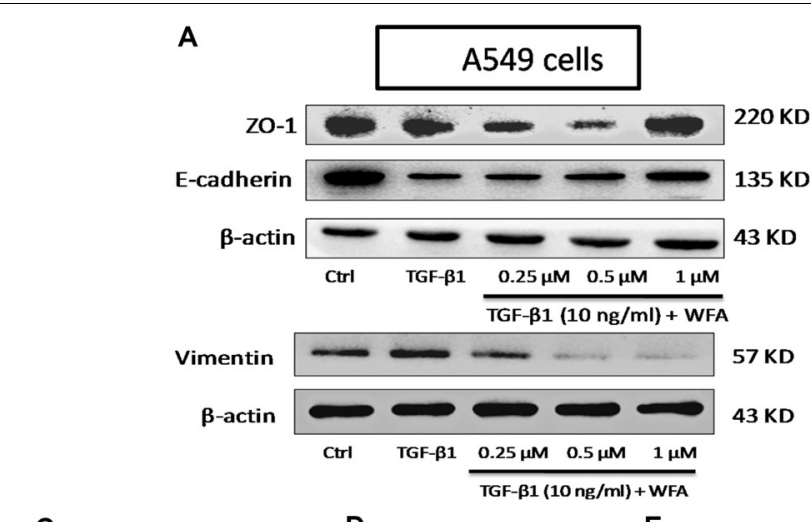

C

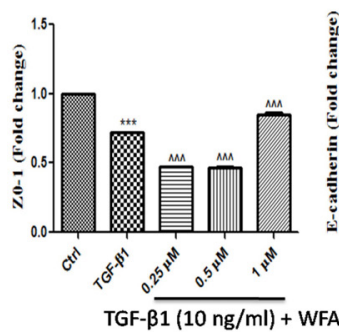

D

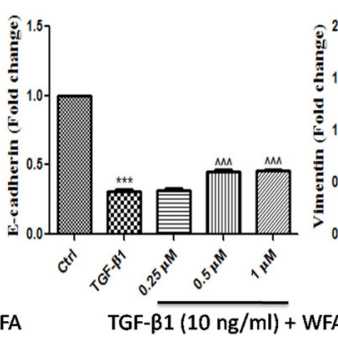

B

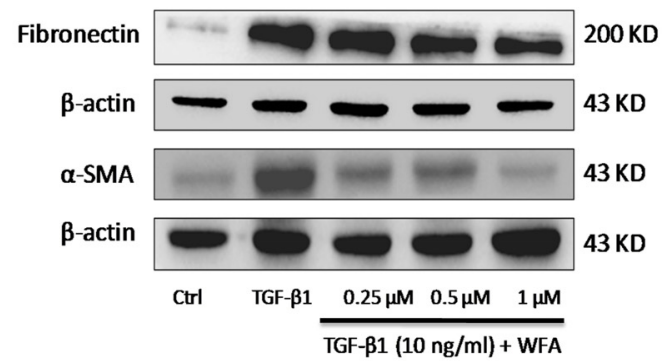

$\mathbf{F}$

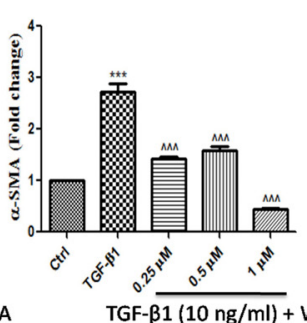

G

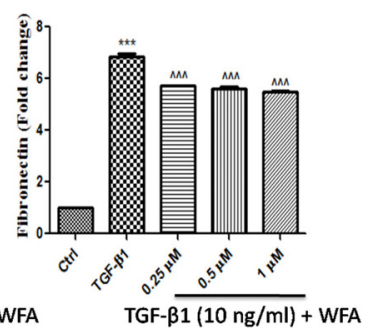

FIGURE 2 | Effect of WFA on EMT related cell markers in vitro studied using western blot analysis. (A) A549 cells, (B) HFL1 cells, and (C-G) indicate graphical representation of quantified EMT protein expression using Image J software. (C) ZO-1, (D) E-cadherin, (E) Vimentin, (F) $\alpha$-SMA, and (G) Fibronectin. Statistical significance was tested using one way ANOVA, ${ }^{* * *} p<0.001$ of TGF- $\beta 1$ versus control; ${ }^{\wedge} \uparrow p<0.001$ of WFA with TGF- $\beta 1$ versus TGF- $\beta 1$ alone.

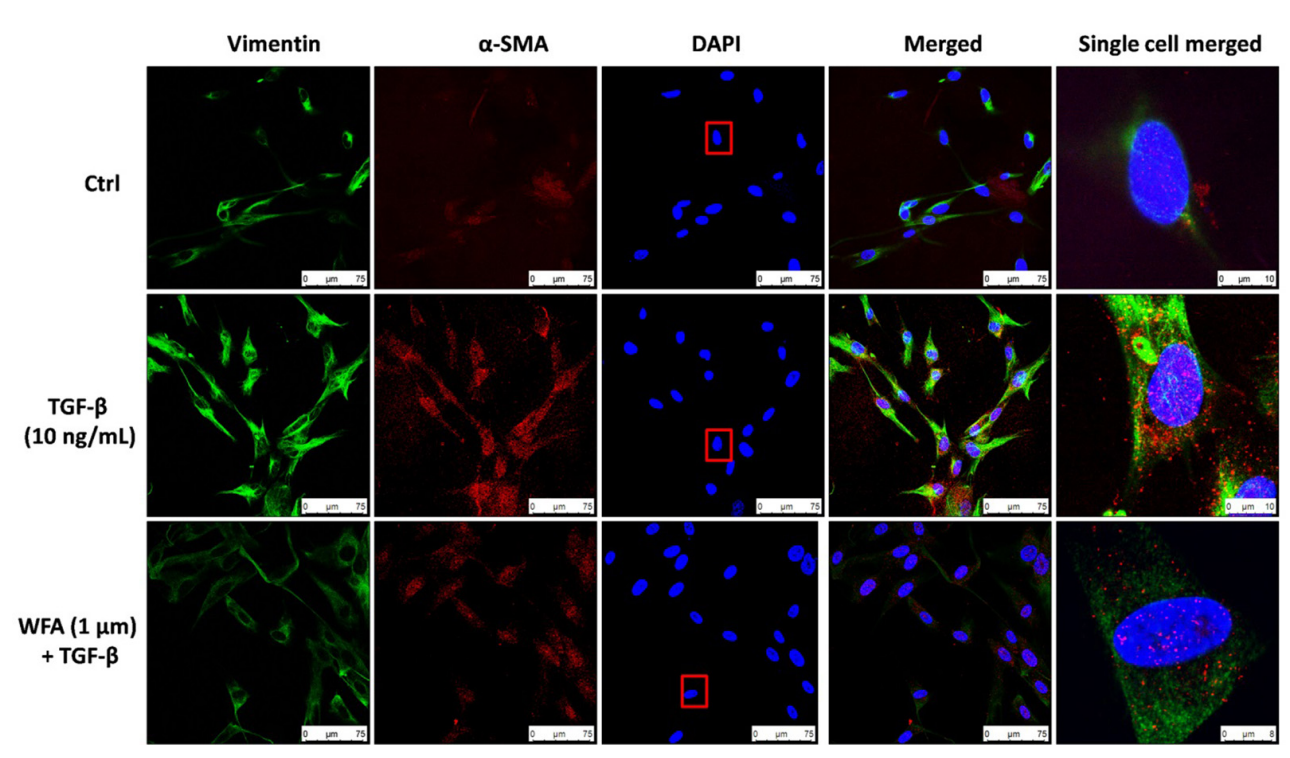

FIGURE 3 | Immunofluoresence evidence for decreased expression of Vimentin and $\alpha$-SMA proteins by WFA in lung fibroblasts. HFL1 cells were co-stained with antibodies against Vimentin (green-FITC) and $\alpha$-SMA (red-rhodamine), while nuclei were stained with DAPI (blue). The overlay of two proteins and nuclei were shown as merged image. A single cell was randomly selected to significantly view the downregulation of these proteins by WFA on TGF- $\beta 1$ stimulation as highlighted in a rectangular box of DAPI stain. Single cell merged represents the overlay of Vimentin and $\alpha$-SMA expression along with DAPI of the selected cell. WFA at $1 \mu \mathrm{M}$ concentration significantly reduced the expression of TGF- $\beta 1$ stimulated Vimentin and $\alpha$-SMA. Images were captured using confocal microscope (Leica TCS SP8 Laser Scanning Spectral Confocal).

as a central mediator in fibrosis was significantly increased in TGF- $\beta 1$ treated cells and WFA decreased CTGF expression in a concentration dependent manner (Figures $\mathbf{4 A}, \mathbf{H}$ ). WFA effects on collagen $1 \mathrm{~A} 1$ and collagen $3 \mathrm{~A} 2$ were evaluated for their expression on TGF- $\beta 1$ stimulation and found significant reduction in the expression of these proteins compared to 


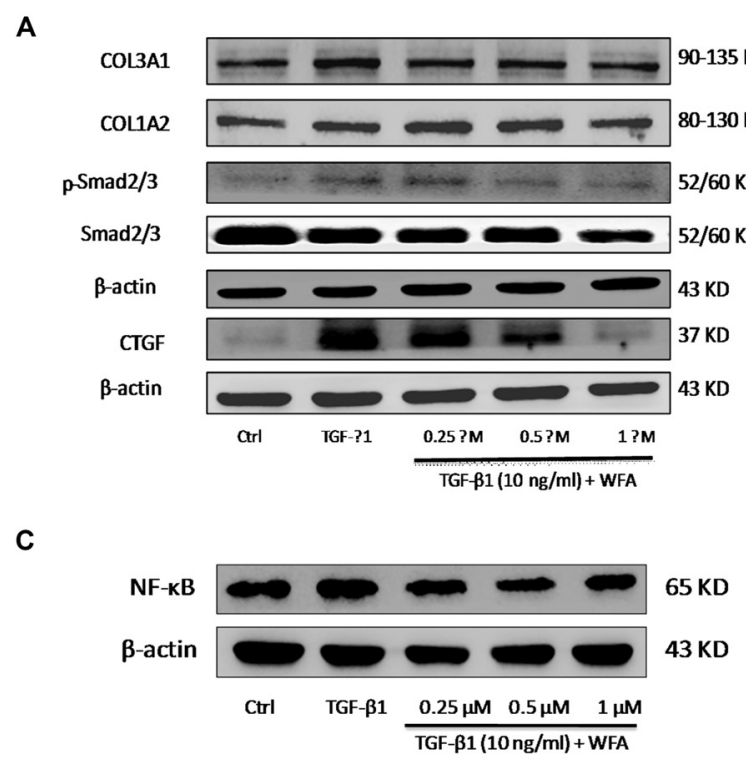

B

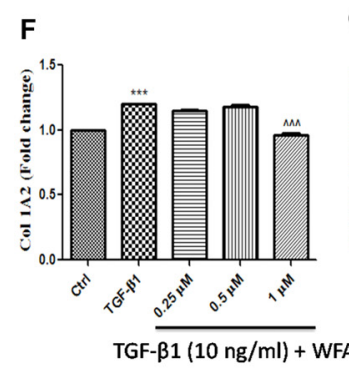

$\mathrm{K}$

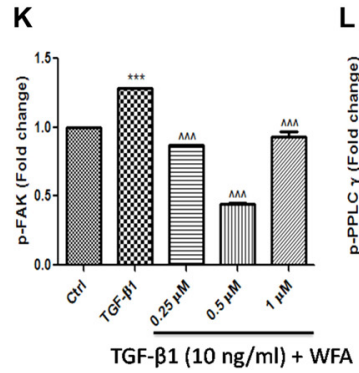

G

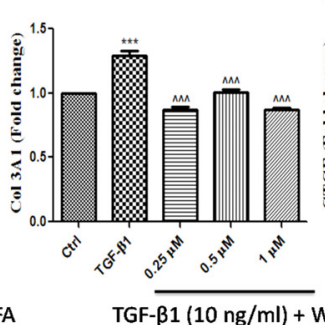

L

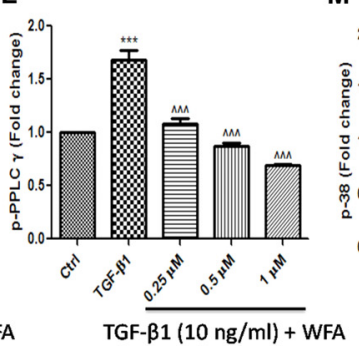

M

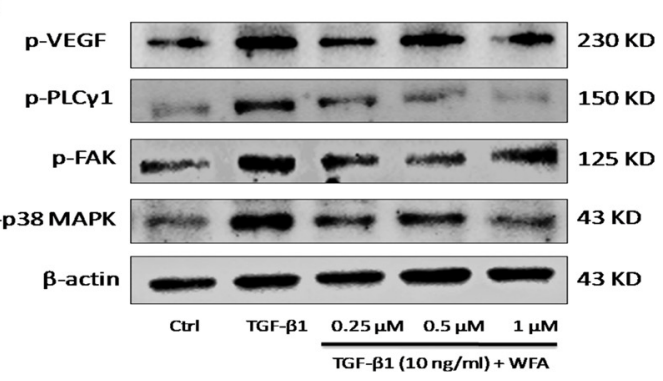

D

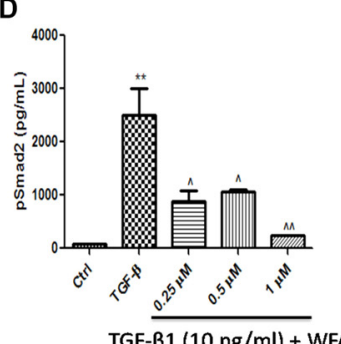

E

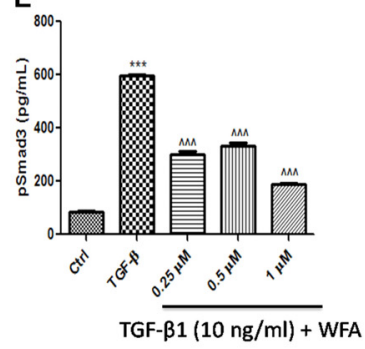

H $\mathbf{I}$ J
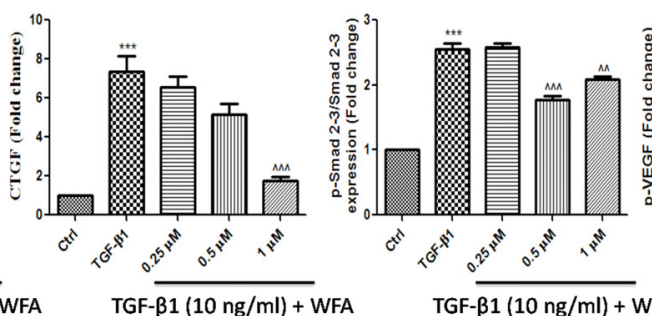

$J$

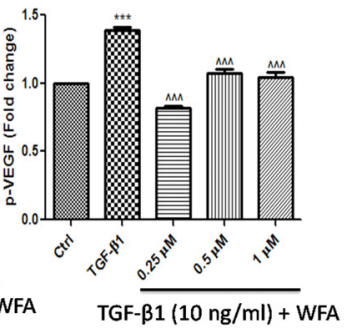

N
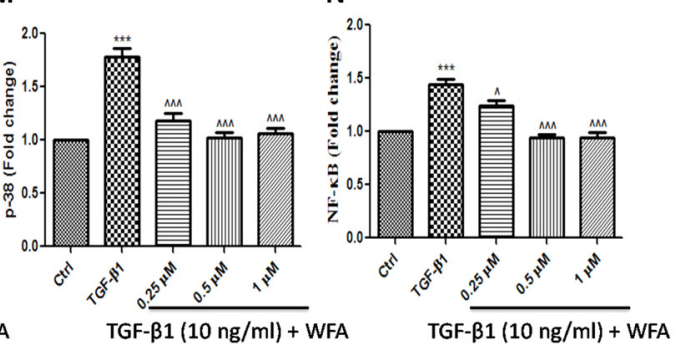

FIGURE 4 | Effect of WFA on fibrotic, inflammation, and angiogenic proteins on HFL1 cells studied using immunoblot analysis. Representation of WFA on (A) fibrotic

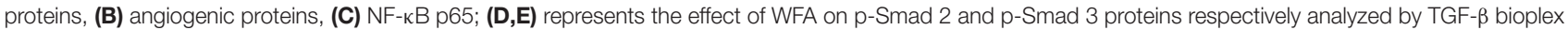
analysis kit. (F-N) Indicate graphical representation of quantified protein expression. (F) Col 1A2, (G) Col 3A1, (H) CTGF, (I) p-Smad 2-3/Smad 2-3 expression, (J) p-VEGF, (K) p-FAK, (L) p-PPLC $\gamma 1$, (M) p-38 MAPK, and (N) NF-кB p65. Statistical significance was tested using one way ANOVA, ** $p<0.01$, *** $p<0.001$ of TGF- $\beta 1$ versus control; $\wedge p 0.05,{ }^{\wedge} p<0.01,{ }^{\wedge} \wedge p<0.001$ of WFA with TGF- $\beta 1$ versus TGF- $\beta 1$ alone.

TGF- $\beta 1$ treated cells (Figures $4 \mathbf{F}, \mathbf{G}$ ). To confirm the antifibrotic effects of WFA mediated by Smad 2/3 signaling, in vitro fibroblasts cell lysates were investigated for their expression using TGF- $\beta$ signaling 6-plex magnetic bead based kit (Figures 4D,E). Bioplex assay results implicated the amelioration of $\mathrm{p}$-Smad 2 and $\mathrm{p}$-Smad 3 proteins by WFA intervention on TGF$\beta 1$ stimulation in a concentration dependent manner which correlated with the results of $\mathrm{p}$-Smad $2 / 3$ expression obtained from western blot. These results demonstrated that WFA may attenuate PF through inhibiting TGF $\beta 1$-Smad $2 / 3$ signaling pathway.

\section{WFA Ameliorated TGF- $\beta 1$ Driven Angiogenesis and Inflammation in Cultured Fibroblasts and Lung Tissue Sections}

WFA is reported to exert anti-angiogenic effects in some cancers and to effectuate the role of WFA as anti-angiogenic agent in PF, some of the significant target proteins of angiogenesis like p-p38 MAPK (mitogen activated protein kinase), p-VEGF (vascular endothelial growth factor), p-FAK (focal adhesion kinase), and p-PLC $\gamma 1$ (phospholipase C) were 

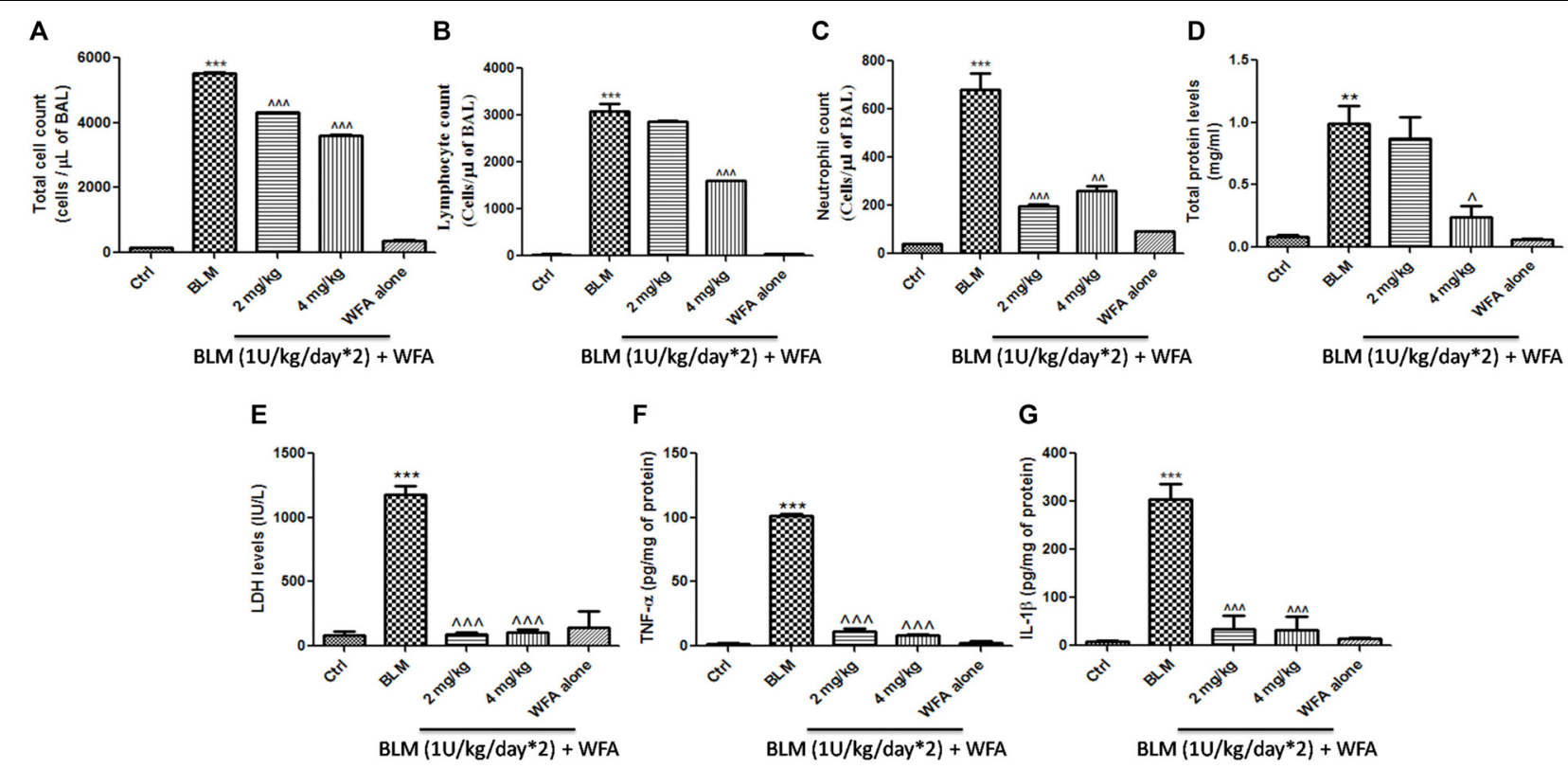

FIGURE 5 | Effect of WFA on BALF cellular infiltrates and lung tissue cytokine expression. BALF obtained from the lungs was used for the measurement of (A) total cell count, (B) lymphocytes, (C) neutrophil count. WFA significantly reduced these infiltrations. BALF was centrifuged and supernatant was estimated for expression of (D) total protein content and (E) LDH levels. Decreased expression of (F) TNF- $\alpha$ and (G) IL-1 $\beta$ in lung tissue supernatants was observed with WFA treatment. Statistical significance was tested using one way ANOVA, ${ }^{* *} p<0.01,{ }^{* * *} p<0.001$ of TGF- $\beta 1$ versus Ctrl; $p<0.05,{ }^{\wedge} p<0.01,{ }^{\wedge} p<0.001$ of WFA with TGF- $\beta 1$ versus TGF- $\beta 1$ alone.

evaluated (Figure 4B). Notable increase in expression of the aforementioned proteins was observed in TGF- $\beta 1$ treated HFL1 cells. WFA treatment resulted in significant decreased expression of p-p38 MAPK and its key effector molecule p-VEGF concentration dependently. Further, direct intracellular signaling molecules of VEGF including p-FAK and p-PLC $\gamma 1$ were significantly attenuated by WFA, suggesting the possible role of WFA as anti-angiogenic agent in ameliorating PF. Consistent with this, $\mathrm{p}$-VEGF expression in BLM treated lung sections was significantly ameliorated by WFA at both doses (Figures 4J-M). As inflammation is one of the critical phases in fibrotic progression, effect of WFA on key inflammatory mediator, NF- $\kappa$ B p65 was evaluated. WFA significantly decreased the enhanced expression of NF- $\mathrm{B}$ p 65 in a concentration dependent manner (Figures 4C,N).

\section{Preventive Effects of WFA on Lung Injury and Fibrosis in BLM Induced Murine Model}

Withaferin A significantly decreased the total number of infiltrated cells in BALF which were elevated in BALF collected from BLM induced murine lungs (Figure 5A). Likewise, WFA significantly decreased the infiltrations of lymphocytes and neutrophils in a dose-dependent manner in BLM treated mice (Figures 5B,C). In parallel, WFA decreased the levels of BALF total protein content in BLM challenged mice, suggesting that WFA may attenuate lung microvascular leakage (Figure 5D). Furthermore, WFA also inhibited the lung damage induced by BLM illustrated by the decrease in LDH activity in BALF
(Figure 5E). In addition to the recruitment of lymphocytes and neutrophils, the inflammatory phase of BLM is also featured by significant lung edema due to severe lung injury and ECM deposition, as measured by lung to body weight index which was substantially decreased by WFA (Figure 6A). Excessive collagen deposition in lung tissues of BLM treated group was reflected by increase in soluble collagen levels and hydroxyproline content respectively (Figures 6D,E). WFA reduced this BLM induced hydroxyproline and soluble collagen levels in a dose-dependent manner demonstrating the antifibrotic effect of WFA. Further, we examined the effect of WFA on surrogate parameters of oxidative and nitrative stress including glutathione levels and nitric oxide content respectively (Figures 6B,C). WFA augmented the expression of glutathione and decreased the nitric oxide levels in lung tissues.

\section{WFA Restored Histological Changes, Decreased Collagen Content, and Mast Cell Infiltration in Lungs of BLM Challenged Mice}

To validate whether WFA exerts anti-fibrotic effects by modulating histological changes, we performed Hematoxylin and Eosin (H\&E) staining to observe key morphological alveolar changes while Masson's trichrome and picrosirius red stains were performed to evaluate collagen deposition and toluidine blue staining to detect extent of mast cell infiltration (Figure 7). A standard quantitative analysis based on improved Ashcroft scoring system was done in H\&E stained sections to examine 


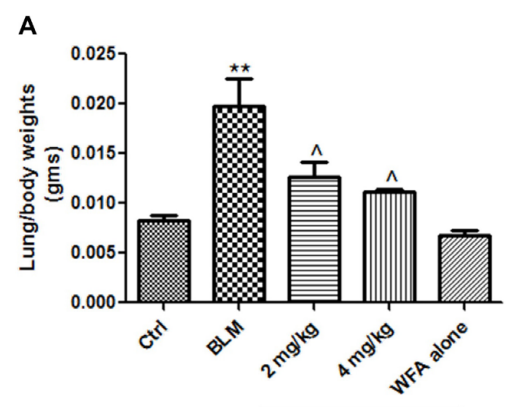

$\operatorname{BLM} \overline{\left(1 \mathrm{U} / \mathrm{kg} / \text { day*}^{*} 2\right)+\text { WFA }}$

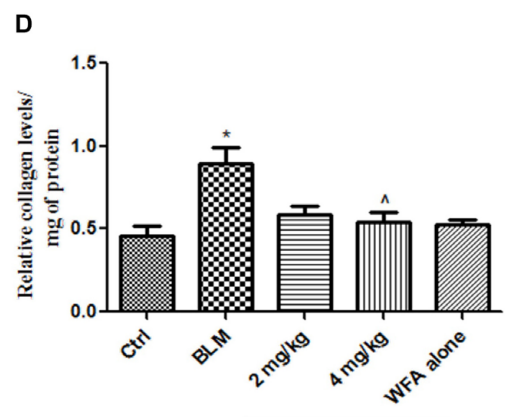

$\operatorname{BLM} \overline{\left(1 \mathrm{U} / \mathrm{kg} / \text { day }^{*} 2\right)+\text { WFA }}$

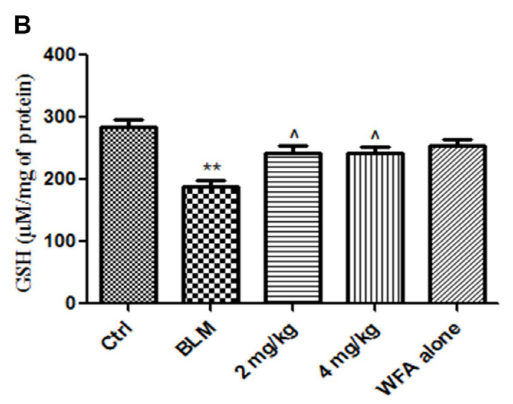

$\operatorname{BLM} \overline{\left(1 \mathrm{U} / \mathrm{kg} / \text { day }^{*} 2\right)+\text { WFA }}$

E

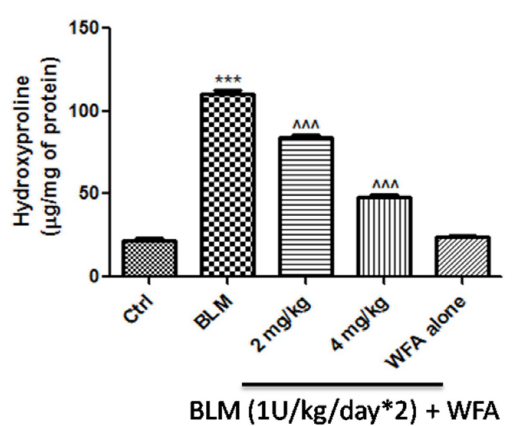

C

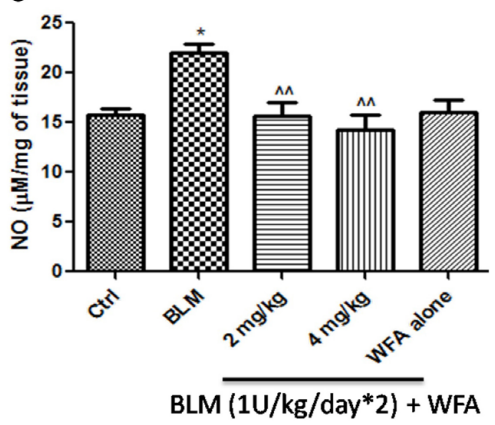

F

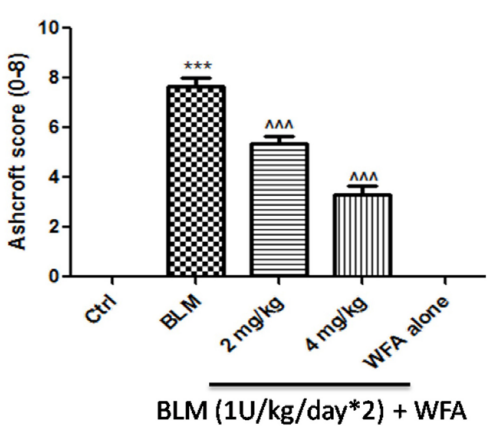

FIGURE 6 | Effect of WFA on lung biochemical parameters and fibrotic markers. (A) Lung to body weight index was measured on the day of study termination; WFA treatment (B) elevated the levels of glutathione content and $\mathbf{( C )}$ reduced the expression of lung nitric oxide in BLM challenged mice. WFA inhibited the collagen expression evident from (D) sircol assay and (E) hydroxyproline assay. (F) Indicates the Ashcroft scoring of H\&E stained lung tissues based on the progression of fibrosis. Statistical significance was tested using one way ANOVA, ${ }^{*} p<0.05,{ }^{* *} p<0.01,{ }^{* * *} p<0.001$ of TGF- $\beta 1$ versus control; ${ }^{\wedge} p<0.05$, ${ }^{\wedge} p<0.01$,

$\wedge \wedge p<0.001$ of WFA with TGF- $\beta 1$ versus TGF- $\beta 1$ alone.

the histological changes (Figure 6F). H\&E stained BLM treated lung tissues showed markedly increased alveolar thickness and obliteration of pulmonary musculature with fibrotic masses, while control lung tissues exhibited no fibrotic burden with normal lung architecture. WFA treatment at $2 \mathrm{mg} / \mathrm{kg}$ reduced the fibrous obliteration; excluding entailed single fibrotic masses while WFA at $4 \mathrm{mg} / \mathrm{kg}$ resulted in lung architecture devoid of fibrotic masses but with slightly enlarged alveoli and was comparable to normal lung architecture. In accordance with the observed restoration of histological changes, the anti-fibrotic effect of WFA was further supported by Masson's trichrome and picrosirius red stains, in which WFA reduced the increased collagen deposition induced by BLM. Toluidine blue staining of lung sections illustrated decreased density of accumulated mast cell infiltration in WFA treated groups compared to BLM challenged mice.

\section{Anti-inflammatory, Anti-fibrotic, and EMT Inhibitory Effects of WFA in Vivo}

To investigate whether WFA modulates the production of inflammatory cytokines including IL- $1 \beta$ and TNF- $\alpha$, we evaluated their expression by ELISA in lung tissue supernatants, which was ameliorated upon treatment with WFA (Figures 5F,G). Further, immunoblot assay revealed that WFA treatment decreased the expression of decisive inflammatory cytokine, NF- $\mathrm{B}$ p 65 in lung tissue. In addition,
WFA dramatically ameliorated the EMT signaling matrix proteins and fibrotic events following BLM induction. WFA substantially increased the expression of epithelial marker E-cadherin, ZO-1 and decreased mesenchymal markers including $\alpha$-SMA. Moreover, WFA attenuated the protein expression of pivotal fibrotic markers including TGF- $\beta 1$, vimentin, collagen $3 \mathrm{~A} 1$ and $\mathrm{p}$-Smad $2 / 3$ in dose-dependent manner, thus illustrating that the anti-fibrotic potential of WFA was mediated via TGF- $\beta /$ Smad signaling (Figure 8). Next, we performed immunohistochemical staining for proteins $\alpha$-SMA, vimentin, NF- $\mathrm{B}$ p 65, and p-VEGF in lung sections to measure the extent of myofibroblast transformation, inflammation, and angiogenesis, respectively (Figure 9). Immunostaining in various regions of the lung revealed significant decrease in the distribution and immunoreactivity of $\alpha$-SMA, vimentin, and NF- $\kappa$ B p65 proteins by WFA dose-dependently. These results indicate that WFA bears the potential to inhibit inflammation, EMT, ECM, fibrotic responses, and angiogenesis in BLM challenged mice.

\section{DISCUSSION}

Pulmonary fibrosis (PF) is defined as one of the serious kind of chronic and progressive fibrotic disorders of interstitial lung diseases of unknown etiology. Prevalence of PF is rapidly 


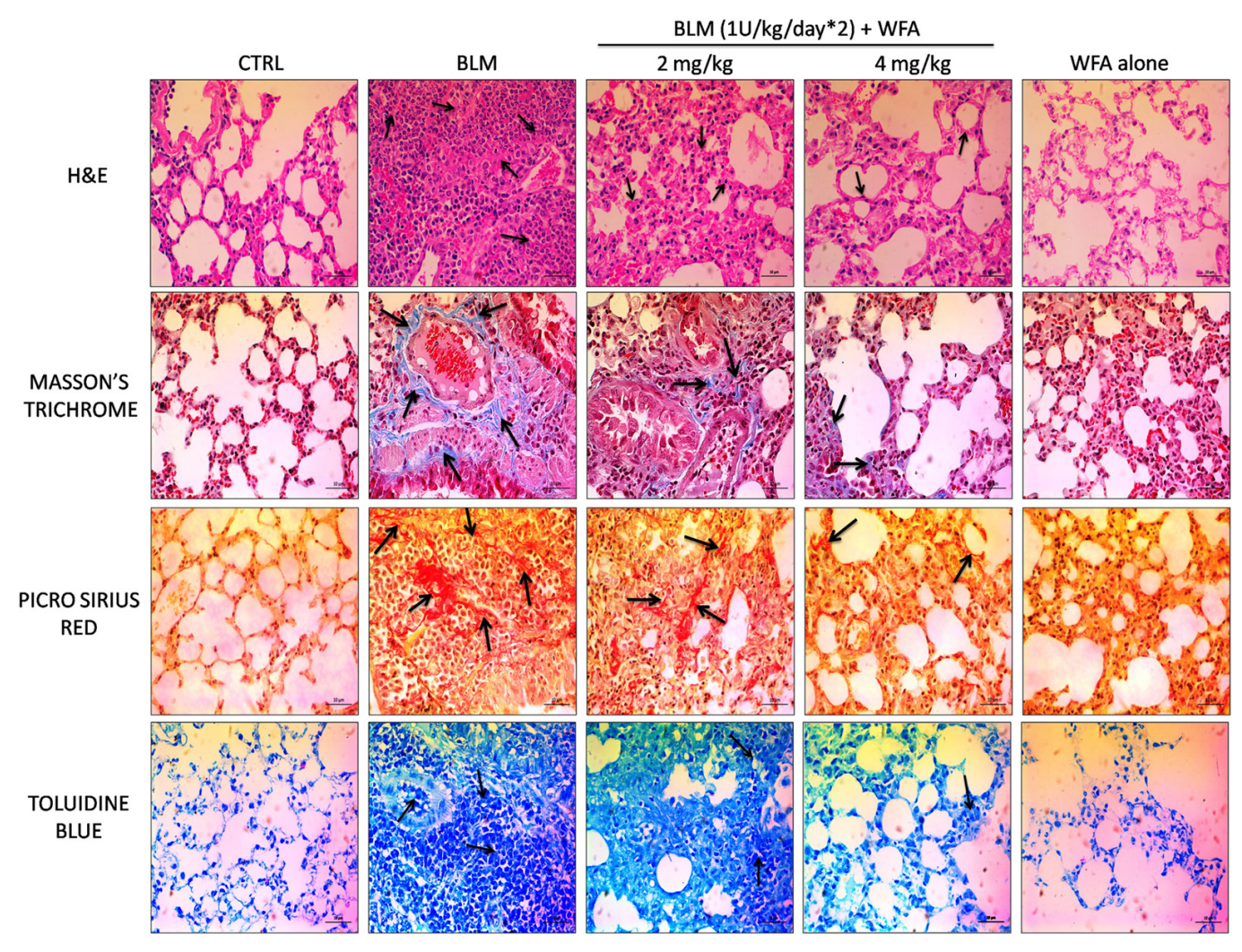

FIGURE 7 | Effect of WFA on histological changes in lung tissues at 28 day post BLM induction. Photomicrographs exhibit staining of mice lung tissues with H\&E, Masson's trichrome, picrosirius red, and toluidine blue as shown from top to bottom. Arrows indicate the extent of pathological features of respective stains. WFA treated lung sections reduced the severity of lung damage as shown in H\&E stained tissues, decreased collagen content as evident from blue and red color of Masson's and picrosirius red stains respectively, and reduced the mast cell accumulation reflected from decreased blue color of WFA treated lung sections. Magnification: 400X.

increasing ranging from 1.25 to 23.4 cases per 100,000 population in Europe, 16.3 to 17.4 per 100,000 population in United States and has turned into a major public health problem worldwide with a survival rate of less than 5 years (Ley et al., 2011; Nalysnyk et al., 2012; Lee et al., 2014). Unmet clinical needs provoke further research to identify and validate potential therapeutic targets and agents. In the present study, TGF- $\beta 1$ induced in vitro and BLM induced in vivo fibrotic models were employed to evaluate the effect of WFA as an anti-fibrotic agent (Xu et al., 2007; Moeller et al., 2008). WFA, a steroidal lactone from Indian traditional herb, Withania somnifera is reported to cause disruption of vimentin intermediate filaments, thereby destabilizing the collagen mRNA that reflects its anti-fibrotic effect (Challa et al., 2012). This bioactive constituent also possesses potent anti-inflammatory activity by inhibiting key inflammatory cytokine NF- $\mathrm{kB}$ (Martorana et al., 2015). Thus the role of WFA as a therapeutic agent against PF involving the matricellular proteins, inflammatory mediators, and fibrotic markers at molecular level has been demonstrated in this study. We also investigated the possible role of WFA on TGF- $\beta 1$ induced angiogenesis in cultured fibroblasts and in vivo (Figure 10).

Initially, we investigated the effects of WFA on cell viability on A549 and HFL1 cells and based on the results, 0.25,
0.5 , and $1 \mu \mathrm{M}$ concentrations of WFA were selected for further molecular studies. Since PF is a result of uncontrolled wound healing, ability of the cells to migrate and proliferate is considered as initial stage of wound repair (Betensley et al., 2016). Effect of WFA on cellular migration was performed and results of the study demonstrated that WFA significantly blocked the proliferation of fibroblasts as evident from wider wound gap in WFA treated cells as compared to control cells, which is consistent with the reported studies of WFA in colon cancer HCT116 cells (Choi and Kim, 2015). Mounting evidence suggest that A549 (lung type-II alveolar epithelial) cells undergo obvious EMT transformation and play a crucial role in pathogenesis of PF; accompanied by increased expression of mesenchymal markers and decreased expression of epithelial markers that results in excess ECM deposition (Özbek et al., 2010). Further lung matrix homeostasis and whole fibrotic events can be well-assayed in HFL1 cells, where TGF- $\beta 1$ prominently stimulates myofibroblast formation (Clark et al., 1997). Therefore, we explored EMT inhibition properties in A549 and HFL1 cells due to predominant EMT occurrence in both the cell lines, but lung matrix homeostasis and whole fibrotic events can be well-assayed only in HFL1 cells, thus anti-fibrotic events of Withaferin A 


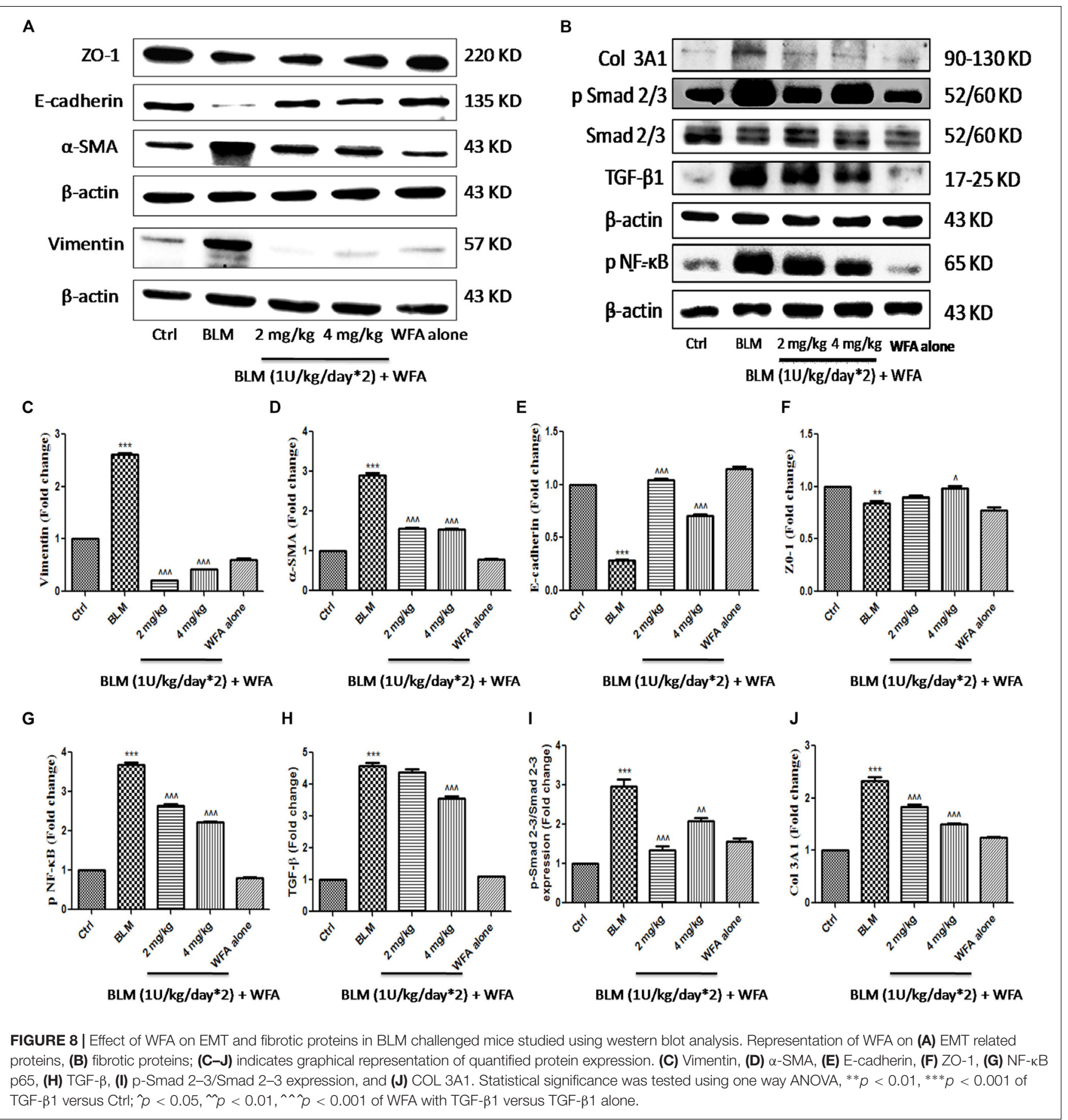

was further investigated only in HFL1 cells in the present study.

During EMT progression, a typical epithelial marker E-cadherin is repressed and switches to expression of $\mathrm{N}$-cadherin (Maeda et al., 2005). Similarly, another important epithelial cell marker is ZO-1, a tight junction membrane associated protein whose expression is decreased during the EMT progression and is considered as a reliable indicator of EMT (Reichert et al., 2000). We evaluated this possibility and found that expression of both epithelial markers E-cadherin and ZO-1 to be remarkably decreased upon TGF- $\beta 1$ stimulation and WFA restored the decreased levels of these proteins in concentration dependent manner. Consistently, increased E-cadherin and ZO-1 expression by WFA in BLM challenged mice was observed in this study. By contrast, $\alpha$-SMA and vimentin are mesenchymal biomarkers whose expression is aberrantly increased as EMT progresses (Kokkinos et al., 2007; Ding et al., 2014). Vimentin is one of the cytoskeleton proteins that regulate functions of a 


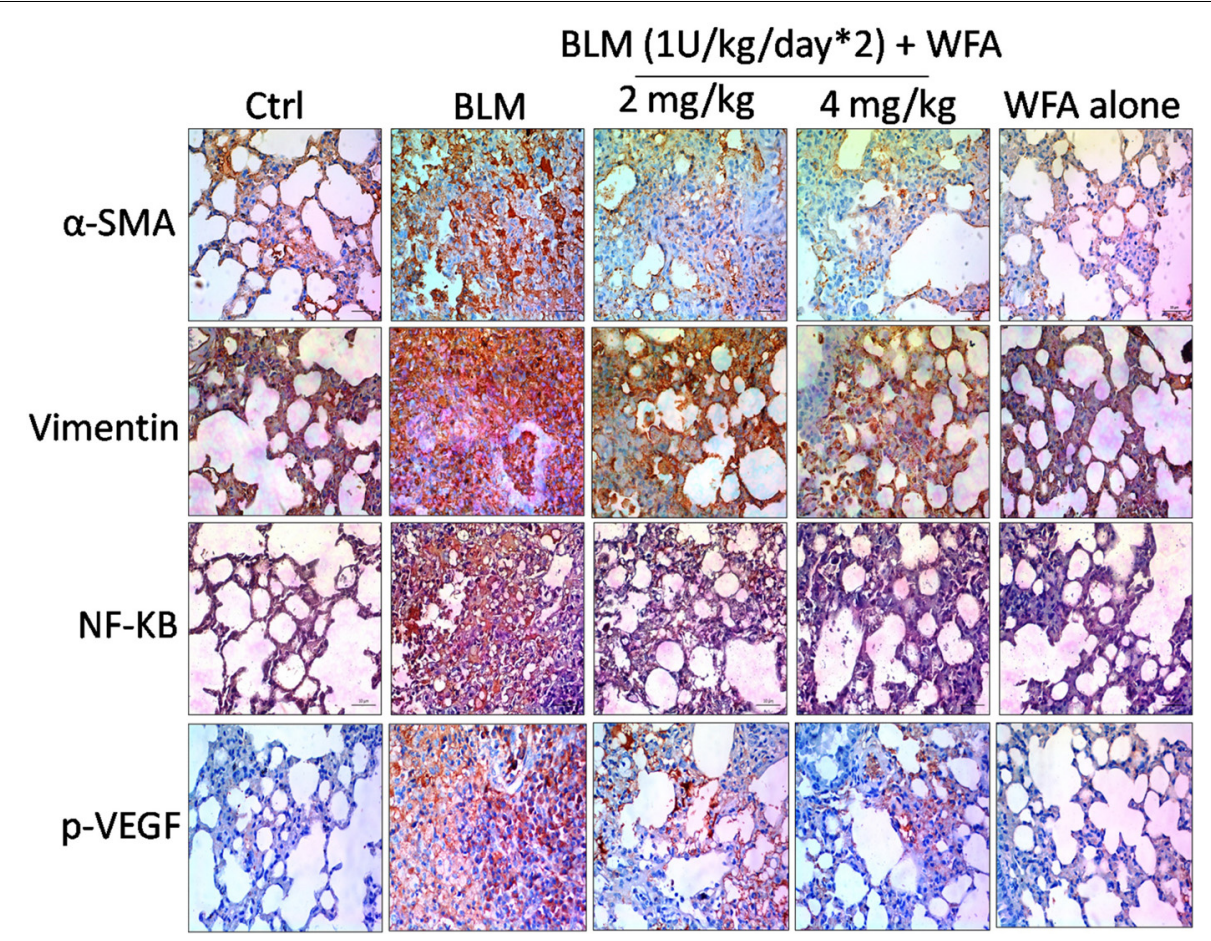

FIGURE 9 | Effect of WFA on EMT, inflammatory and angiogenic proteins assayed using immunohistochemistry. Lung sections after processing were stained for antibodies against $\alpha$-SMA, Vimentin, NF-кB p65, and p-VEGF proteins to evaluate the effect of WFA on expression of respective proteins. Significant elevated expression of all these proteins were observed in BLM challenged mice reflected from brown coloration and WFA substantially reduced the increased expression of proteins $\alpha$-SMA, Vimentin, and NF-кB p65 in dose-dependent manner evidenced from decreased immunopositive cells on WFA treatment, while there was no considerable immunopositive cells in control and WFA alone groups. Magnification: 400X.

plethora of cellular and biochemical processes and propagates EMT together with actin. Furthermore vimentin stabilizes collagen mRNA expression and aids in excess collagen deposition (Challa et al., 2012). The role of WFA as a vimentin inhibitor has been documented in several studies and was therefore evaluated for its effect on vimentin down-regulation in PF. As expected, protein expression of $\alpha$-SMA and vimentin was significantly increased in TGF- $\beta 1$ stimulated HFL1 cells and WFA mitigated this effect. In support of this, immunofluoresence assay of these proteins performed in HFL1 cells revealed their decreased expression on treatment with WFA. Moreover, we have investigated the expression of $\alpha$-SMA and vimentin in lung tissues of BLM induced mice and the results revealed a significant dose-dependent decrease in the expression of these proteins by WFA. Further to confirm their expression in lung tissues, immunohistochemistry was performed and a notable decreased expression of $\alpha$-SMA and vimentin by WFA was observed as evident by their decreased immunopositivity. Overall the findings of immunoblotting and immunohistochemistry of $\alpha$-SMA and vimentin suggest the potential of EMT inhibition in PF by WFA. Further, the protective effect of EMT inhibition by WFA was confirmed using immunofluoresence assay performed on proteins $\alpha$-SMA and vimentin using confocal microscope.

During the course of fibrosis, the subsequent step of EMT is ECM deposition. Fibronectin, a ubiquitous glycoprotein of ECM that plays a role in tissue remodeling is considered as a decisive contributing factor to switch from normal wound healing to deregulated fibrosis (Petrini et al., 2017). Excess fibronectin is produced from endothelial cells and fibroblasts upon stimulation of growth factors including platelet derived growth factor and TGF- $\beta 1$ (Hocevar et al., 1999; Zhao et al., 2017). Hence, the role of WFA on fibronectin was evaluated and we observed dramatic decrease in expression of fibronectin in WFA treated HFL1 cells. CTGF is another matricellular protein that enables persistent fibrosis by triggering EMT, facilitates ECM deposition and remodeling (Weston et al., 2003). Further, several lines of evidence reported that increased CTGF expression contributes to elevated $\alpha$-SMA expression that are implicated in PF (Zhang et al., 2004). The present study therefore evaluated the effect of WFA on CTGF and significant decreased expression of CTGF was observed on WFA treated TGF- $\beta 1$ stimulated cells in concentration dependent manner. Additionally, the role of collagen, the most widely expressed protein of connective tissue as a pivotal ECM component has been demonstrated in several studies (Di Lullo et al., 2002). Collagen 1 and collagen 3 dependent cellular processes are found to be detrimental in PF (Hansen et al., 2016). It is well-documented from a recent study that TGF- $\beta 1$ activated CTGF perhaps enhances the expression of collagen 1 mediated Smad 3 signaling (Cheng et al., 2015). As a result, collagen expression on WFA treatment both in vitro and in vivo was investigated using a series of experiments for further confirmation. Both collagen 1A2 and collagen 3A1 levels 


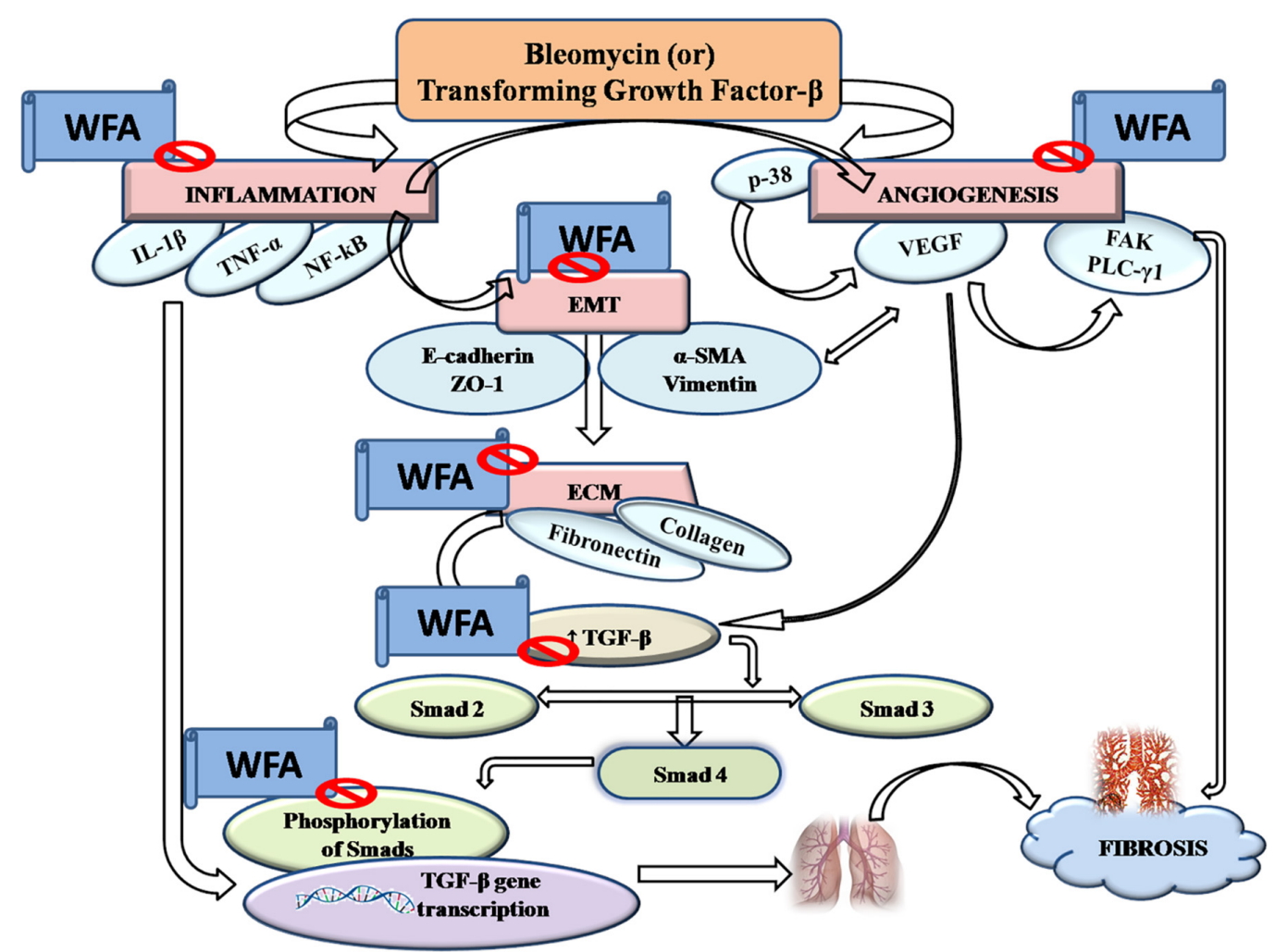

FIGURE 10 | Graphical abstract: pictorially represents the amelioration of pulmonary fibrosis by Withaferin A via modulation of various signaling cascades.

were substantially decreased by WFA in TGF- $\beta 1$ stimulated cells. Further, results of hydroxyproline and sircol assay evidenced the reduced collagen content in lung tissues of BLM challenged mice by WFA which were consistent with the results of Masson's trichrome and picrosirius red stained lung sections respectively, wherein WFA ameliorated collagen levels in dose-dependent manner. In addition, immunoblotting analysis of lung tissues also revealed reduced collagen $3 \mathrm{~A} 1$ expression upon WFA treatment.

The development of fibrotic events is possible due to deregulation of several signaling cascades including Smad dependent and independent pathways (Derynck and Zhang, 2003). Aberrant TGF- $\beta 1$ activation has been reported in several studies of BLM induced model of PF (Khalil et al., 2002; Zhao et al., 2002). As speculated, TGF- $\beta 1$ expression was significantly elevated in BLM induced mice and a subsequent decreased TGF- $\beta 1$ expression was observed in lung tissues treated with WFA. Moreover, intracellular phosphorylation of Smad $2 / 3$ is a major determinant in mediating TGF- $\beta 1$ induced fibrotic events (Evans et al., 2003; Gu et al., 2007; Walton et al., 2017). The present study is aimed at investigating the potential of WFA in suppressing Smad activation. In context with the established reports, immunoblot and bioplex analysis results of the study exhibited significant increase of $\mathrm{p}$-Smad $2 / 3$ expression in TGF- $\beta 1$ stimulated cells and BLM induced lung tissues while, WFA significantly ameliorated the phosphorylation of Smad 2/3. Overall, these findings revealed WFA as a potential inhibitor of TGF- $\beta 1$ mediated Smad signaling cascade in attenuating PF.
Toward the direction of oxidative and nitrative stress in PF, WFA augmented the levels of glutathione content and curbed down nitric oxide levels in lung tissues. Extensive influx of inflammatory cells particularly lymphocytes and neutrophils in BALF of oropharyngeally aspirated BLM mice was observed, as reported in previous studies (Karpel et al., 1989; Obayashi et al., 1997). WFA reduced pulmonary inflammatory cytological infiltrates of BALF (lymphocytes and neutrophils) following BLM aspiration and restored the expression of $\mathrm{LDH}$ and total protein content, the key inflammatory biomarkers of PF (Newton et al., 2017). In agreement with the attenuation of cellular infiltrates by WFA, lung tissue infiltration was also reduced by WFA as evident from pathological findings featured by reduced ECM deposition from decreased alveolar septal thickening. Besides BAL cell infiltrations, mast cell deposition in lung tissues aggravates $\mathrm{PF}$ and WFA significantly diminished mast cell accumulation as reflected by toluidine blue staining (Wygrecka et al., 2013). Further, inflammatory cytokines including IL- $1 \beta$, TNF- $\alpha$, and NF-кB leave no gap in triggering fibrotic events (Wilson et al., 2010; Hou et al., 2018). Moreover, WFA is a profound inhibitor of inflammatory responses in both cellular and animal models and thus was investigated in the present study and was found to alleviate the expression of those proteins in lung tissues upon WFA treatment. WFA as a potent inhibitor of NF- $\mathrm{BB}$ in T-cell mediated adaptive immune reactions prompted us to investigate its role on NF- $\mathrm{BB}$ in PF (Maitra et al., 2009). Remarkable decrease in expression of NF- $\kappa \mathrm{B}$ p 65 was observed 
in HFL1 cells and lung tissues from immunoblot studies. Further, immunohistochemistry results of NF- $\kappa$ B p 65 protein confirmed the potential of WFA in down regulating inflammation associated with PF.

Angiogenesis plays a pivotal role in PF as demonstrated by elevated levels of angiogenenic chemokines in both experimental animal models and tissue specimens collected from IPF patients (Hanumegowda et al., 2012; Ziora et al., 2015). Further, it has been strongly revealed that VEGF, an angiogenic promoter is aberrantly expressed in lung specimens of PF patients suggesting angiogenesis as one of the prime factors in $\mathrm{PF}$ pathogenesis (Richter et al., 2005). TGF- $\beta 1$ directly activates the pivotal angiogenic growth factor VEGF and also stimulates VEGF activation by various down streaming signaling mediators including $\alpha$-SMA, fibronectin, and CTGF (Ferrari et al., 2009; Liu et al., 2014). Moreover, inflammatory cytokines including NF- $\kappa$ B and p38 MAPK also aggravates angiogenesis by phosphorylating the key effector molecule VEGF (Ye and Yuan, 2007; Kim et al., 2014). FAK, a cytoplasmic non-receptor tyrosine kinase protein is found to play a role in myofibroblasts differentiation and thus propagates angiogenesis mediated PF (Zhao and Guan, 2011). FAK inhibition attenuated EMT process in a study of BLM induced PF (Lagares et al., 2012). Further, PLC- $\gamma 1$ is a downstream mediator of VEGF that is over expressed in angiogenesis (Lawson et al., 2003). It was inferred from the results of current study that WFA substantially reduced the expression of p-p38 MAPK, p-VEGF, p-FAK, and p-PLC $\gamma 1$ proteins demonstrating the potential of WFA in attenuating angiogenesis driven PF. Taken together, the present study throws light on the significance of interplay of various pro-fibrotic

\section{REFERENCES}

American Thoracic Society and European Respiratory Society (2002). American thoracic society/European respiratory society international multidisciplinary consensus classification of the idiopathic interstitial Pneumonias. This joint statement of the American thoracic society (ATS), and the European respiratory society (ERS) was adopted by the ATS board of directors, June 2001 and by the ERS executive committee, June 2001. Am. J. Respir. Crit. Care Med. 165, 277-304. doi: 10.1164/ajrccm.165.2.ats01

Bale, S., Sunkoju, M., Reddy, S. S., Swamy, V., and Godugu, C. (2016). Oropharyngeal aspiration of bleomycin: an alternative experimental model of pulmonary fibrosis developed in Swiss mice. Indian J. Pharmacol. 48, 643-648. doi: 10.4103/0253-7613.194859

Barrett, C. S. X., Millena, A. C., and Khan, S. A. (2017). TGF- $\beta$ effects on prostate cancer cell migration and invasion require FosB. Prostate 77, 72-81. doi: 10.1002 /pros. 23250

Betensley, A., Sharif, R., and Karamichos, D. (2016). A systematic review of the role of dysfunctional wound healing in the pathogenesis and treatment of idiopathic pulmonary fibrosis. J. Clin. Med. 6:2. doi: 10.3390/jcm6010002

Challa, A. A., Vukmirovic, M., Blackmon, J., and Stefanovic, B. (2012). WithaferinA reduces type I collagen expression in vitro and inhibits development of myocardial fibrosis in vivo. PLoS One 7:e42989. doi: 10.1371/journal.pone. 0042989

Cheng, J. C., Chang, H. M., Fang, L., Sun, Y.-P., and Leung, P. C. K. (2015). TGF- $\beta 1$ up-regulates connective tissue growth factor expression in human granulosa cells through Smad and ERK1/2 signaling pathways. PLoS One 10:e126532. doi: 10.1371 /journal.pone.0126532

Chilosi, M., Poletti, V., and Rossi, A. (2012). The pathogenesis of COPD and IPF: distinct horns of the same devil? Respir. Res. 13:3. doi: 10.1186/14659921-13-3 and cellular matrix proteins, pro-inflammatory cytokines, and angiogenic factors in pathogenesis of PF and emphasizes on targeting such integral cellular processes for heading toward development of effective therapeutic interventions. WFA could possibly fit into this role of mitigating PF by inhibiting EMT and ECM progression, inflammation, and angiogenesis. However, further decisive studies are requisite for establishing WFA as a promising therapeutic intervention for treatment of PF.

\section{AUTHOR CONTRIBUTIONS}

CG and SB designed the research work. SB performed the research with PV and MS. SB and CG wrote the manuscript. All authors reviewed the final version of the manuscript.

\section{FUNDING}

This study was supported financially by Department of Pharmaceuticals, Ministry of Chemicals and Fertilizers, Government of India.

\section{ACKNOWLEDGMENTS}

The authors acknowledge the technical assistance from Indian Institute of Chemical Technology (CSIR-IICT), Hyderabad, India. They also thank Anil Kumar Kalvala for his kind support and technical assistance in confocal imaging.

Choi, B. Y., and Kim, B. W. (2015). Withaferin-A inhibits colon cancer cell growth by blocking STAT3 transcriptional activity. J. Cancer Prev. 20, 185-192. doi: 10.15430/JCP.2015.20.3.185

Clark, R. A., McCoy, G. A., Folkvord, J. M., and McPherson, J. M. (1997). TGF- $\beta 1$ stimulates cultured human fibroblasts to proliferate and produce tissue-like fibroplasia: a fibronectin matrix-dependent event. J. Cell. Physiol. 170, 69-80. doi: 10.1002/(SICI)1097-4652(199701)170:1<69::AID-JCP8>3.0.CO;2-J

Derynck, R., and Zhang, Y. E. (2003). Smad-dependent and Smad-independent pathways in TGF- $\beta$ family signalling. Nature 425, 577-584. doi: 10.1038/ nature02006

Di Lullo, G. A., Sweeney, S. M., Korkko, J., Ala-Kokko, L., and San Antonio, J. D. (2002). Mapping the ligand-binding sites and disease-associated mutations on the most abundant protein in the human, type I collagen. J. Biol. Chem. 277, 4223-4231. doi: 10.1074/jbc.M110709200

Ding, L., Zhang, Z., Shang, D., Cheng, J., Yuan, H., Wu, Y., et al. (2014). $\alpha$-Smooth muscle actin-positive myofibroblasts, in association with epithelialmesenchymal transition and lymphogenesis, is a critical prognostic parameter in patients with oral tongue squamous cell carcinoma. J. Oral Pathol. Med. 43, 335-343. doi: 10.1111/jop.12143

Evans, R. A., Tian, Y. C., Steadman, R., and Phillips, A. O. (2003). TGF-beta1mediated fibroblast-myofibroblast terminal differentiation-the role of Smad proteins. Exp. Cell Res. 282, 90-100. doi: 10.1016/S0014-4827(02)00015-0

Ferrari, G., Cook, B. D., Terushkin, V., Pintucci, G., and Mignatti, P. (2009). Transforming growth factor-beta 1 (TGF-beta1) induces angiogenesis through vascular endothelial growth factor (VEGF)-mediated apoptosis. J. Cell. Physiol. 219, 449-458. doi: 10.1002/jcp.21706

Godugu, C., Doddapaneni, R., and Singh, M. (2017). Honokiol nanomicellar formulation produced increased oral bioavailability and anticancer effects in triple negative breast cancer (TNBC). Colloids Surf. B Biointerfaces 153, 208-219. doi: 10.1016/j.colsurfb.2017.01.038 
Godugu, C., Patel, A. R., Doddapaneni, R., Marepally, S., Jackson, T., and Singh, M. (2013). Inhalation delivery of Telmisartan enhances intratumoral distribution of nanoparticles in lung cancer models. J. Control. Release 172, 86-95. doi: 10.1016/j.jconrel.2013.06.036

Gu, L., Zhu, Y. J., Yang, X., Guo, Z.-J., Xu, W.-B., and Tian, X.-L. (2007). Effect of TGF-beta/Smad signaling pathway on lung myofibroblast differentiation. Acta Pharmacol. Sin. 28, 382-391. doi: 10.1111/j.1745-7254.2007.00468.x

Guevara, I., Iwanejko, J., Dembińska-Kieć, A., Pankiewicz, J., Wanat, A., Anna, P., et al. (1998). Determination of nitrite/nitrate in human biological material by the simple Griess reaction. Clin. Chim. Acta 274, 177-188. doi: 10.1016/S00098981(98)00060-6

Hahm, E. R., Lee, J., and Singh, S. V. (2014). Role of mitogen-activated protein kinases and $\mathrm{Mcl}-1$ in apoptosis induction by withaferin $\mathrm{A}$ in human breast cancer cells. Mol. Carcinog. 53, 907-916. doi: 10.1002/mc.22050

Hansen, N. U. B., Karsdal, M. A., Brockbank, S., Cruwys, S., Rønnow, S., and Leeming, D. J. (2016). Tissue turnover of collagen type I, III and elastin is elevated in the PCLS model of IPF and can be restored back to vehicle levels using a phosphodiesterase inhibitor. Respir. Res. 17:76. doi: 10.1186/s12931016-0394-8

Hanumegowda, C., Farkas, L., and Kolb, M. (2012). Angiogenesis in pulmonary fibrosis. Chest 142, 200-207. doi: 10.1378/chest.11-1962

Heyninck, K., Lahtela-Kakkonen, M., Van der Veken, P., Haegeman, G., and Vanden Berghe, W. (2014). Withaferin A inhibits NF-кB activation by targeting cysteine 179 in IKK $\beta$. Biochem. Pharmacol. 91, 501-509. doi: 10.1016/j.bcp. 2014.08.004

Hocevar, B. A., Brown, T. L., and Howe, P. H. (1999). TGF-beta induces fibronectin synthesis through a c-Jun N-terminal kinase-dependent, Smad4-independent pathway. EMBO J. 18, 1345-1356. doi: 10.1093/emboj/18.5.1345

Hou, J., Ma, T., Cao, H., Chen, Y., Wang, C., Chen, X., et al. (2018). TNF- $\alpha$-induced NF- $\kappa \mathrm{B}$ activation promotes myofibroblast differentiation of LR-MSCs and exacerbates bleomycin-induced pulmonary fibrosis. J. Cell. Physiol. 233, 2409-2419. doi: 10.1002/jcp.26112

Jiang, C., Huang, H., Liu, J., Wang, Y., Lu, Z., and Xu, Z. (2012). Adverse events of pirfenidone for the treatment of pulmonary fibrosis: a meta-analysis of randomized controlled trials. PLoS One 7:e47024. doi: 10.1371/journal.pone. 0047024

Karpel, J. P., Aldrich, T. K., Mitsudo, S., and Norin, A. J. (1989). Lung lymphocytes in bleomycin-induced pulmonary disease. Lung 167, 163-172. doi: 10.1007/ BF02714945

Kasai, H., Allen, J. T., Mason, R. M., Kamimura, T., and Zhang, Z. (2005). TGF-betal induces human alveolar epithelial to mesenchymal cell transition (EMT). Respir. Res. 6:56. doi: 10.1186/1465-9921-6-56

Khalil, N., Parekh, T. V., O’Connor, R. N., and Gold, L. I. (2002). Differential expression of transforming growth factor-beta type I and II receptors by pulmonary cells in bleomycin-induced lung injury: correlation with repair and fibrosis. Exp. Lung Res. 28, 233-250. doi: 10.1080/019021402753570527

Kim, G., Kim, T. H., Hwang, E. H., Chang, K. T., Hong, J. J., and Park, J. H. (2017). Withaferin A inhibits the proliferation of gastric cancer cells by inducing G2/M cell cycle arrest and apoptosis. Oncol. Lett. 14, 416-422. doi: 10.3892/ol.2017. 6169

Kim, H. Y., Park, S. Y., Lee, S. W., Lee, H. R., Lee, W. S., Rhim, B. Y., et al. (2014). Inhibition of HMGB1-induced angiogenesis by cilostazol via SIRT1 activation in synovial fibroblasts from rheumatoid arthritis. PLoS One 9:e104743. doi: 10.1371/journal.pone.0104743

King, T. E., Pardo, A., and Selman, M. (2011). Idiopathic pulmonary fibrosis. Lancet 378, 1949-1961. doi: 10.1016/S0140-6736(11)60052-4

Kokkinos, M. I., Wafai, R., Wong, M. K., Newgreen, D. F., Thompson, E. W., and Waltham, M. (2007). Vimentin and epithelial-mesenchymal transition in human breast cancer-observations in vitro and in vivo. Cells Tissues Organs 185, 191-203. doi: 10.1159/000101320

Kolosova, I., Nethery, D., and Kern, J. A. (2011). Role of Smad2/3 and p38 MAP kinase in TGF- $\beta 1$-induced epithelial-mesenchymal transition of pulmonary epithelial cells. J. Cell. Physiol. 226, 1248-1254. doi: 10.1002/jcp. 22448

Lagares, D., Busnadiego, O., García-Fernández, R. A., Kapoor, M., Liu, S., Carter, D. E., et al. (2012). Inhibition of focal adhesion kinase prevents experimental lung fibrosis and myofibroblast formation. Arthritis Rheum. 64, 1653-1664. doi: $10.1002 /$ art.33482
Lawson, N. D., Mugford, J. W., Diamond, B. A., and Weinstein, B. M. (2003). phospholipase C gamma-1 is required downstream of vascular endothelial growth factor during arterial development. Genes Dev. 17, 1346-1351. doi: $10.1101 / \operatorname{gad} .1072203$

Lee, A. S., Mira-Avendano, I., Ryu, J. H., and Daniels, C. E. (2014). The burden of idiopathic pulmonary fibrosis: an unmet public health need. Respir. Med. 108, 955-967. doi: 10.1016/j.rmed.2014.03.015

Ley, B., Collard, H. R., and King, T. E. (2011). Clinical course and prediction of survival in idiopathic pulmonary fibrosis. Am. J. Respir. Crit. Care Med. 183, 431-440. doi: 10.1164/rccm.201006-0894CI

Li, M., Luan, F., Zhao, Y., Hao, H., Zhou, Y., Han, W., et al. (2016). Epithelialmesenchymal transition: an emerging target in tissue fibrosis. Exp. Biol. Med. 241, 1-13. doi: 10.1177/1535370215597194

Limjunyawong, N., Mitzner, W., and Horton, M. R. (2014). A mouse model of chronic idiopathic pulmonary fibrosis. Physiol. Rep. 2:e00249. doi: 10.1002/ phy2.249

Liu, S. C., Chuang, S. M., Hsu, C. J., Tsai, C.-H., Wang, S. W., and Tang, C. H. (2014). CTGF increases vascular endothelial growth factordependent angiogenesis in human synovial fibroblasts by increasing miR-210 expression. Cell Death Dis. 5:e1485. doi: 10.1038/cddis.2014.453

Madhusudan, M., Zameer, F., Naidu, A., M N, N. P., Dhananjaya, B. L., and Hegdekatte, R. (2016). Evaluating the inhibitory potential of Withania somnifera on platelet aggregation and inflammation enzymes: an in vitro and in silico study. Pharm. Biol. 54, 1936-1941. doi: 10.3109/13880209.2015.1123729

Maeda, M., Johnson, K. R., and Wheelock, M. J. (2005). Cadherin switching: essential for behavioral but not morphological changes during an epitheliumto-mesenchyme transition. J. Cell Sci. 118, 873-887. doi: 10.1242/jcs.01634

Maitra, R., Porter, M. A., Huang, S., and Gilmour, B. P. (2009). Inhibition of NF- $\kappa$ B by the natural product Withaferin A in cellular models of Cystic Fibrosis inflammation. J. Inflamm. 6:15. doi: 10.1186/1476-9255-6-15

Martorana, F., Guidotti, G., Brambilla, L., and Rossi, D. (2015). Withaferin A inhibits nuclear factor- $\kappa \mathrm{B}$-dependent pro-inflammatory and stress response pathways in the astrocytes. Neural Plast. 2015:381964. doi: 10.1155/2015/ 381964

Maurya, D. K., Nandakumar, N., and Devasagayam, T. P. A. (2011). Anticancer property of gallic acid in A549, a human lung adenocarcinoma cell line, and possible mechanisms. J. Clin. Biochem. Nutr. 48, 85-90. doi: 10.3164/jcbn. 11-004FR

Moeller, A., Ask, K., Warburton, D., Gauldie, J., and Kolb, M. (2008). The bleomycin animal model: a useful tool to investigate treatment options for idiopathic pulmonary fibrosis? Int. J. Biochem. Cell Biol. 40, 362-382. doi: 10.1016/j.biocel.2007.08.011

Moron, M. S., Depierre, J. W., and Mannervik, B. (1979). Levels of glutathione, glutathione reductase and glutathione S-transferase activities in rat lung and liver. Biochim. Biophys. Acta 582, 67-78. doi: 10.1016/0304-4165(79) 90289-7

Moustakas, A., and Heldin, C. H. (2016). Mechanisms of TGF $\beta$-induced epithelialmesenchymal transition. J. Clin. Med. 5:E63. doi: 10.3390/jcm5070063

Nakao, A., Imamura, T., Souchelnytskyi, S., Kawabata, M., Ishisaki, A., Oeda, E., et al. (1997). TGF-beta receptor-mediated signalling through Smad2, Smad3 and Smad4. EMBO J. 16, 5353-5362. doi: 10.1093/emboj/16.17.5353

Nalysnyk, L., Cid-Ruzafa, J., Rotella, P., and Esser, D. (2012). Incidence and prevalence of idiopathic pulmonary fibrosis: review of the literature. Eur. Respir. Rev. 21, 355-361. doi: 10.1183/09059180.00002512

Newton, D. A., Lottes, R. G., Paintlia, M. K., Ryan, R. M., and Baatz, J. E. (2017). "Lactate dehydrogenase expression and activity is altered in alveolar type II cells from patients with idiopathic pulmonary fibrosis," in Proceedings of the American Thoracic Society International Conference A72 MECHANISMS DRIVING FIBROSIS, New York, NY.

Richeldi, L., du Bois, R. M., Raghu, G., Azuma, A., Brown, K. K., Costabel, U., et al. (2015). Efficacy and safety of nintedanib in idiopathic pulmonary fibrosis. N. Engl. J. Med. 370, 2071-2082. doi: 10.1056/NEJMoa1402584

Obayashi, Y., Yamadori, I., Fujita, J., Yoshinouchi, T., Ueda, N., and Takahara, J. (1997). The role of neutrophils in the pathogenesis of idiopathic pulmonary fibrosis. Chest 112, 1338-1343. doi: 10.1378/chest.112.5.1338

Özbek, S., Balasubramanian, P. G., Chiquet-Ehrismann, R., Tucker, R. P., and Adams, J. C. (2010). The evolution of extracellular matrix. Mol. Biol. Cell 21, 4300-4305. doi: 10.1091/mbc.E10-03-0251 
Patel, K., Chowdhury, N., Doddapaneni, R., Boakye, C. H. A., and Singh, M. (2015). Piperlongumine for enhancing oral bioavailability and cytotoxicity of docetaxel in triple negative breast cancer. J. Pharm. Sci. 104, 4417-4426. doi: $10.1002 /$ jps. 24637

Petrini, I., Barachini, S., Carnicelli, V., Galimberti, S., Modeo, L., Boni, R., et al. (2017). ED-B fibronectin expression is a marker of epithelial-mesenchymal transition in translational oncology. Oncotarget 8, 4914-4921. doi: 10.18632/ oncotarget.13615

Reichert, M., Müller, T., and Hunziker, W. (2000). The PDZ domains of zonula occludens-1 induce an epithelial to mesenchymal transition of Madin-Darby canine kidney I cells. Evidence for a role of $\beta$-catenin/Tcf/Lef signaling. J. Biol. Chem. 275, 9492-9500. doi: 10.1074/jbc.275.13.9492

Richter, A., Maughan, E., Perkins, G., Nathani, N., and Thickett, D. (2005). VEGF levels in pulmonary fibrosis. Thorax 60:171. doi: 10.1136/thx.2004.031500

Todd, N. W., Luzina, I. G., and Atamas, S. P. (2012). Molecular and cellular mechanisms of pulmonary fibrosis. Fibrogenesis Tissue Repair. 5:11. doi: 10.1186/1755-1536-5-11

Vanden Berghe, W., Sabbe, L., Kaileh, M., Haegeman, G., and Heyninck, K. (2012). Molecular insight in the multifunctional activities of Withaferin A. Biochem. Pharmacol. 84, 1282-1291. doi: 10.1016/j.bcp.2012.08.027

Veerappan, A., Reid, A. C., O'Connor, N., Mora, R., Brazin, J. A., Estephan, R., et al. (2012). Mast cells are required for the development of renal fibrosis in the rodent unilateral ureteral obstruction model. Am. J. Physiol. Renal Physiol. 302, F192-F204. doi: 10.1152/ajprenal.00562.2010

Verrecchia, F., and Mauviel, A. (2002). Transforming growth factor- $\beta$ signaling through the Smad pathway: role in extracellular matrix gene expression and regulation. J. Invest. Dermatol. 118, 211-215. doi: 10.1046/j.1523-1747.2002. 01641.x

Vogel, B., Siebert, H., Hofmann, U., and Frantz, S. (2015). Determination of collagen content within picrosirius red stained paraffin-embedded tissue sections using fluorescence microscopy. MethodsX 2, 124-134. doi: 10.1016/j. mex.2015.02.007

Walton, K. L., Johnson, K. E., and Harrison, C. A. (2017). Targeting TGF- $\beta$ Mediated SMAD signaling for the prevention of fibrosis. Front. Pharmacol. 8:461. doi: 10.3389/fphar.2017.00461

Weston, B. S., Wahab, N. A., and Mason, R. M. (2003). CTGF mediates TGF- $\beta$-induced fibronectin matrix deposition by upregulating active $\alpha 5 \beta 1$ integrin in human mesangial cells. J. Am. Soc. Nephrol. 14, 601-610. doi: 10.1097/01.ASN.0000051600.53134.B9

Wilson, M. S., Madala, S. K., Ramalingam, T. R., Gochuico, B. R., Rosas, I. O., Cheever, A. W., et al. (2010). Bleomycin and IL-1 $\beta$-mediated pulmonary fibrosis is IL-17A dependent. J. Exp. Med. 207, 535-552. doi: 10.1084/jem.2009 2121

Wilson, M. S., and Wynn, T. A. (2009). Pulmonary fibrosis: pathogenesis, etiology and regulation. Mucosal Immunol. 2, 103-121. doi: 10.1038/mi.2008.85
Wygrecka, M., Dahal, B. K., Kosanovic, D., Petersen, F., Taborski, B., von Gerlach, S., et al. (2013). Mast cells and fibroblasts work in concert to aggravate pulmonary fibrosis: role of transmembrane SCF and the PAR-2/PKC- $\alpha /$ Raf1/p44/42 signaling pathway. Am. J. Pathol. 182, 2094-2108. doi: 10.1016/j. ajpath.2013.02.013

Xu, Q., Norman, J. T., Shrivastav, S., Lucio-Cazana, J., and Kopp, J. B. (2007). In vitro models of TGF-beta-induced fibrosis suitable for high-throughput screening of antifibrotic agents. Am. J. Physiol. Renal Physiol. 293, F631-F640. doi: 10.1152/ajprenal.00379.2006

Ye, J., and Yuan, L. (2007). Inhibition of p38 MAPK reduces tumor conditioned medium-induced angiogenesis in co-cultured human umbilical vein endothelial cells and fibroblasts. Biosci. Biotechnol. Biochem. 71, 1162-1169. doi: 10.1271/ bbb. 60617

Zhang, C., Meng, X., Zhu, Z., Liu, J., and Deng, A. (2004). Connective tissue growth factor regulates the key events in tubular epithelial to myofibroblast transition in vitro. Cell Biol. Int. 28, 863-873. doi: 10.1016/j.cellbi.2004.09.003

Zhang, Y. E. (2017). Non-Smad signaling pathways of the TGF- $\beta$ family. Cold Spring Harb. Perspect. Biol. 9:a022129. doi: 10.1101/cshperspect.a022129

Zhao, J., Shi, W., Wang, Y.-L., Chen, H., Bringas, P., Datto, M. B., et al. (2002). Smad3 deficiency attenuates bleomycin-induced pulmonary fibrosis in mice. Am. J. Physiol. Lung Cell. Mol. Physiol. 282, L585-L593. doi: 10.1152/ajplung. 00151.2001

Zhao, X., and Guan, J. L. (2011). Focal adhesion kinase and its signaling pathways in cell migration and angiogenesis. Adv. Drug Deliv. Rev. 63, 610-615. doi: 10.1016/j.addr.2010.11.001

Zhao, X., Hao, J., Duan, H., Rong, Z., and Li, F. (2017). Phosphoinositide 3-kinase/protein kinase $\mathrm{B} /$ periostin mediated platelet-derived growth factorinduced cell proliferation and extracellular matrix production in lupus nephritis. Exp. Biol. Med. 242, 160-168. doi: 10.1177/1535370216668050

Ziora, D., Jastrzębski, D., Adamek, M., Czuba, Z., Kozielski, J. J., Grzanka, A., et al. (2015). Circulating concentration of markers of angiogenic activity in patients with sarcoidosis and idiopathic pulmonary fibrosis. BMC Pulm. Med. 15:113. doi: 10.1186/s12890-015-0110-3

Conflict of Interest Statement: The authors declare that the research was conducted in the absence of any commercial or financial relationships that could be construed as a potential conflict of interest.

Copyright (c) 2018 Bale, Venkatesh, Sunkoju and Godugu. This is an open-access article distributed under the terms of the Creative Commons Attribution License (CC BY). The use, distribution or reproduction in other forums is permitted, provided the original author(s) and the copyright owner are credited and that the original publication in this journal is cited, in accordance with accepted academic practice. No use, distribution or reproduction is permitted which does not comply with these terms. 